\title{
Network Structure of Intercity Trips by Chinese Residents under Different Travel Modes: A Case Study of the Spring Festival Travel Rush
}

\author{
Rong Zhang (D), Jinghu Pan (D), and Jianbo Lai (D) \\ College of Geography and Environmental Science, Northwest Normal University, Lanzhou 730070, China \\ Correspondence should be addressed to Jinghu Pan; panjh_nwnu@nwnu.edu.cn
}

Received 23 June 2020; Revised 11 March 2021; Accepted 21 March 2021; Published 1 April 2021

Academic Editor: Burçin Bozkaya

Copyright (c) 2021 Rong Zhang et al. This is an open access article distributed under the Creative Commons Attribution License, which permits unrestricted use, distribution, and reproduction in any medium, provided the original work is properly cited.

\begin{abstract}
With the advent of big data, the use of network data to characterize travel has gradually become a trend. Tencent Migration big data can fully, dynamically, immediately, and visually record the trajectories of population migrations with location-based service technology. Here, the daily population flow data of 346 cities during the Spring Festival travel rush in China were combined with different travel modes to measure the spatial structure and spatial patterns of an intercity trip network of Chinese residents. These data were then used for a comprehensive depiction of the complex relationships between the population flows of cities. The results showed that there were obvious differences in the characteristics of urban networks from the perspective of different modes of travel. The intercity flow of aviation trips showed a core-periphery structure with national hub cities as the core distribution. Trips by train showed a core-periphery structure with cities along the national railway artery as the core. This gradually decreased toward hinterland cities. Moreover, the intercity flow of highway trips indicated a spatial pattern of strong local aggregation that matched the population scale.
\end{abstract}

\section{Introduction}

By highlighting social and economic factors, networks of population flow can be developed. For example, social network analysis is an important interdisciplinary research method in recent years from the perspective of the relationships between the behaviors of subjects. The migration and flow of populations are regarded as activities with production factors allocated in space. These factors promote the reagglomeration and diffusion of social and economic factors [1]. Travel has a clear origin and destination, which, together with population flows during certain periods, constitute a population trip network. A population trip network relies on an urban network, with cities as the network nodes. The direction and intensity of population flows represent the relationship between the nodes. The emergence of a floating population not only changes the spatial distribution of the population but also affects the development of the regional economy [2]. It plays an important role in accelerating the development of the urban and rural economy, and it promotes urbanization, upgrades the industrial structure, and optimizes the regional allocation of labor resources [3]. The 2016 Report of China's Floating Population Development estimated that China's floating population reached 247 million in 2015, accounting for $18 \%$ of the total population. In addition, the direction of Chinese population flow has changed in recent years, with the labor force, especially migrant workers, returning from eastern coastal cities to central and western cities, and laborand resource-intensive industries transferring to central and western regions [4].

The phenomenon of population flow around the world cannot be ignored in the development of today's era. The flow of population between cities is represented by a particular type of network structure [5]. Wei et al. [6] proposed that a population flow network is a typical directed-weighted geographic network. Most existing research on population flow in China is concentrated around the Spring Festival $[2,7]$. However, some scholars have analyzed the characteristics of population flow on National 
Day and the subsequent Mid-Autumn Festival [1]. When selecting data, most researchers have traditionally used provincial census data and sample survey data [8-10]. However, with the rapid advancement of globalization and information technology, static data used in traditional research have been unable to meet the requirements for spatial analysis. It is more difficult to explore the increasingly complex relationships between cities using such data $[11,12]$. A census cannot accurately grasp the scale of daily flow between cities and the characteristics of inflow and outflow, nor can it obtain the routes and direction of population migration within a relatively continuous time interval. This is because it only focuses on a specific time period, or analyzes the macro-patterns of population flow under laws of long-term evolution. Thus, it is impossible to analyze the increasingly complex interactions between cities from the perspective of flow space $[13,14]$.

As a direct representation of intercity interconnections and interactions, population migration has been a hot issue for geographers [15]. Current research focuses on longdistance intercity trip networks represented by aviation [16], daily intercity commuting networks represented by highspeed railways [17], and the characteristics and travel modes of intercity trip networks based on time-dependent microblog "check-in" data and network attention data [18]. The traffic routes that residents rely on for intercity trips are important tools for urban internal and external connections, and they reflect the ability and degree of urban connections and communication [19]. To some extent, traffic routes can be regarded as the basic support and key link of an urban network spatial structure. With the development of the social economy, the "spatiotemporal compression" effect caused by high speed travel modes, such as high speed rail and aviation, greatly improves the mobility of residents. Intercity trips are networked, integrated, dynamic, and personalized, and they are time- and mode-dependent. An intercity trip network with different time scales and modes can reflect complex geospatial connections.

Under the effect of globalization, urban space evolves from local space to flow space. The connections between cities form a hierarchical network; the horizontal connection between nodes is the point of emphasis in such a network model. In recent years, research on urban networks has emerged as a new paradigm of geography. Geographers in this field seek to identify the importance and characteristic attributes of urban nodes and analyze the hierarchical structure and relevance of urban networks [20]. Some geographers believe that global cities are the centrality for commanding and controlling global capital. They used a series of network analysis indicators, such as the degree centrality, betweenness centrality, and closeness centrality, to reveal the importance of network nodes [20]. In studies of global city networks based on the index of degree centrality, the centrality and power are usually equal. Boschken [21] and Alderson and Beckfield [22] described the positions of global cities in a network. However, "global cities are influential only insofar as they can influence hinterland cities [23]. Cook et al. [24] pointed out that when focusing on economic exchange, the dominant exchanges (with stronger power) are easier to control and influence exchange behavior, compared to those with a large number of potential opportunities (with higher centrality). Then, Zachary proposed the concepts of recursive centrality and recursive power in 2011 [25], and renamed them, respectively, alter-based centrality and alter-based power [26]. In addition, he thought that, in world city networks, the agglomeration of resource elements such as labor, capital, and information into world cities and the outward diffusion of resource elements from world cities are all a performance of centrality. Centrality is the unification of resource aggregation and diffusion. Power represents the influence and dominance of a city in the process of resource circulation. The power of a city is determined by the location of the network and the role it plays. Neal [25] drew two hypothetical world city network structure diagrams. He thought that, in comparison, the central node of the larger network is "central, but lack of power," and the central node of the smaller network is "power, but relatively lack of center." Through recursion, Neal explained that city centrality and power not only depend on the scale of network connections but also on the capital capacity (such as economic, cultural, and other similar representations) of its own and related branches [27]. Therefore, we selected these two indicators for a comprehensive evaluation of the status of a city in the network.

The objectives of this study were as follows: (1) to evaluate the intercity trip characteristics and intensity of three trip networks during the Spring Festival travel rush using population flow data, to simulate the path of the population flow process in 346 cities in China; (2) to explore spatial differences between the three trip networks, and reveal the complex structural characteristics of the intercity trip network; (3) to analyze the spatial structure of Chinese urban networks and measure the urban network hierarchy and aggregation spatial patterns under different travel modes; and (4) to explore the differences of urban network characteristics under different travel modes and discuss the rationality and necessity of spatiotemporal big data in the study of daily population flow.

\section{Related Work}

A network is composed of abstract nodes and edges of connecting nodes, and it abstractly describes the complex and intertwined objective world [28]. Cities are not isolated in regional space. They have a complex interaction with each other, thus forming an urban network with a specific spatial structure and functional organization [29]. Through the exchange of materials, information, finance, and population flow among cities, the interaction and complementary advantages among cities and regions are strengthened, forming complex networks of different scales and levels [30]. This kind of network takes the city as the center and the element of circulation as the medium. It forms a spatial structure of nodes, axes, and domains in a certain area. Under the background of the acceleration of globalization, the urban system of Western developed countries gradually presents a 
trend of transformation from a hierarchical-scale model to a network model [31]. This prompted scholars to change their perspective and reexamine the new spatial structure of cities. The focus of their attention also changed from the urbanhierarchical scale, spatial form, and functional evolution to the structure and relationships of urban networks $[2,6,32]$. Castells [33] proposed the concept of a "space of flows." Flows, networks, and network nodes are summarized as the basic elements of "flow space." Among them, information flow, population flow, and capital flow are regarded as the flow elements, and companies, enterprises, cities, and countries are regarded as the network nodes. Different flow elements produce different network nodes. The different attributes of network nodes affect the movement of flow elements, as well as the patterns of the entire network. The transformation of an urban hierarchical system and functional division system is jointly driven by the "flow space" and the traditional "local space." The emergence of "flow space" makes the traditional centralized place model; based on the theory of hierarchical scale, it gradually turns to an open, flow-based, and polycentric network model [34]. Xu et al. [2] used network analysis to reveal the relationships between migration data and urban development.

With the development of Internet technology and intelligent terminals, the collection and analysis of resident trip data have diversified. The era of big data makes it possible to obtain resident movement patterns through massive spatial and temporal trajectories of individual granularity. Mobile computing devices with geo-positioning can be used to track individual spatial movements and record spatial and temporal data over a long time with high precision (bus swipecard records, social network "check-in" data, the movement of taxis, etc.) $[35,36]$. In China, many Internet companies provide location-based services to users, such as Baidu, Tencent, and Sina. The data in this study were obtained from the Tencent Migration big data platform (https://heat.qq. com/qianxi.php), and were downloaded using Python. These data were mainly obtained by third-party users using the positioning data provided by the Tencent location service. It covers most users' complete long-distance and short-distance trip behavior by taking the day as the statistical unit. Data on children, the elderly, and those who do not use location-based services are not available. To a certain extent, this avoids the underestimation and virtual increase of data caused by short-distance and long-distance trips. At the same time, the continuous development of geographic information technology facilitates data collection, storage, analysis, and visualization, and provides greater support for the study of the structural characteristics of trip networks $[37,38]$.

Recently, many scholars have used population trip data regarding aviation [39, 40], railways [41], and high speed rail [42] to summarize the spatial connections of national passenger traffic networks. Some scholars have conducted comparative studies of high-speed railways and airline networks in China and revealed laws of regional spatial organization [27]. These studies have enriched the research of different scales of urban network systems to a certain extent. However, they focused on spatial connections and the interaction between the cities from the perspective of a single type of traffic flow. In terms of intercity trip networks, researchers mainly focus on the use of long-distance travel surveys and commuting survey data to directly reveal the characteristics of intercity trip networks. Limtanakool et al. [43] revealed differences in behavior and network structure heterogeneity under different types of travel based on survey data regarding long distance interregional travel in Europe. De Montis et al. [44] analyzed the structural characteristics of intercity travel (commuting) in Italy using a complex network method. Based on the data regarding American aviation flow, Neal [45] systematically discussed the network characteristics of different types of aviation flow (viz., business flow and tourism flow) and different seasons of aviation flow (viz., summer and winter). High precision spatiotemporal information regarding population flow from location-based services provides sufficient and accurate measured flow data for studying travel and population flow. $\mathrm{Li}$ et al. [32] used Baidu migration data to analyze the population flow characteristics during the Spring Festival in China. Wei et al. [46] analyzed the characteristics of a Chinese urban network in the transitional period. These studies used big data to analyze individual and group behavior, and to reflect the spatial behavior, spatial cognition, and connection mode behind it. Such data can be used to reflect the decision-making of individuals and groups with regard to their spatiotemporal behavior, and is becoming a hot research frontier for studying travel and population flow.

\section{Methods and Data Sources}

We used the method of complex network analysis to identify and analyze the structural characteristics of the Chinese residents in an intercity trip network by using indicators such as the dominant flow, alter-based centrality, alter-based power, clustering coefficient, and network cluster structure analysis.

3.1. Dominant Flow. The dominant flow analysis method was first proposed by Nystuen and Dacey [47] in 1961. It is a mature method that simplifies the analysis of an urban network [37]. Briefly, the method involves judging the position of a city in an urban system based on the main factor flow from one city to another, including the maximum dominant flow, the second dominant flow, and other higher dominant flows [48]. In this study, we used dominant flow analysis to recognize the status of a city at the macroscale. The selection of the factor flow was the population flow intensity under different travel modes during the Spring Festival travel rush [20].

\subsection{Alter-Based Centrality and Alter-Based Power.} Tencent population migration data provide the direction and intensity of migration in various cities within a day under different modes of travel. Based on it, we constructed a bidirectional matrix $L=\left(L_{i j}\right)$ to characterize the population 
flow over the course of one day, where $L_{i j}$ is the population flow intensity from city $i$ to city $j$. There are $346 \times 346$ directional weighted asymmetric matrices.

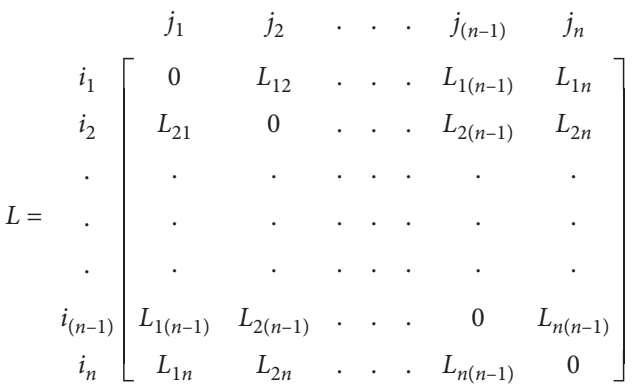

The population flow weight $R_{i j}$ between city $i$ and city $j$ is calculated, and is regarded as the index for calculating the alter-based centrality and alter-based power:

$$
R_{i j}=\frac{L_{i j}^{T}+L_{i j}}{2} .
$$

When measuring the urban alter-based centrality (alterbased power), it is necessary to consider the impact of related cities on the measured city. For the data, there are a number of population flows between certain cities and satellite cities. For example, Langfang accounts for the majority of the population flow associated with Beijing. As a national economic and cultural center, Beijing has a relatively high degree of centrality, which leads to an indirect increase on the centrality of Langfang. Adding the dependency parameter " $d_{i j}$ " can correct the phenomenon that the centrality result is difficult to describe. The status of the urban network and the centrality and power results of the entire network city tend to converge. In comparison, the status of a city with a balanced resource relationship will increase, while the status of a satellite city will decline significantly. This is more in line with the actual development of the city [20]. The formula is as follows:

$$
d_{i j}=\frac{R_{i j}}{\mathrm{WDC}_{i}},
$$

where $\mathrm{WDC}_{i}$ is the weighted degree centrality of city $i$. Based on the correction, the formulas for the alter-based centrality and alter-based power are as follows:

$$
\begin{aligned}
\mathrm{AC}_{i} & =\sum_{j}\left(1-d_{i j}\right) \times R_{i j} \times \mathrm{DC}_{j}, \\
\mathrm{AP}_{i} & =\sum_{j}\left(1-d_{i j}\right) \times \frac{R_{i j}}{\mathrm{DC}_{j}} .
\end{aligned}
$$

3.3. Clustering Coefficient. The clustering coefficient is used to describe the interconnection level of nodes [28]. When certain nodes are closely connected, they can form a network cluster. We calculated the clustering coefficient as follows:

$$
C_{i}=\frac{2 B_{i}}{m_{i}\left(m_{i}-1\right)}
$$

where $C_{i}$ is the clustering coefficient, and $B_{i}$ is the number of paths between the node and the neighboring nodes of $m_{i}$.

3.4. Data Sources. The data in this study were obtained from the Tencent Migration big data platform (https://heat.qq. com/qianxi.php). Tencent is one of the largest Internetintegrated service providers and one of the Internet enterprises with the largest number of service users in China. It mainly involves social networking, communication, games, and other aspects. The representative services are WeChat, QQ, and some Tencent software. In 2018, WeChat monthly active users reached 1.15 billion, and QQ monthly active users reached 650 million. With the ubiquity of smart devices, the number of Tencent users is increasing in China, so these data can cover most regions and users. This is also a new research direction in the study of population mobility.

Tencent location-service data is a value-added service whereby Tencent obtains the location information of mobile terminal users through radio communication networks or external positioning based on the location-based service. Users are provided with corresponding services under the support of a geographic information system platform. Today, mobile phones are widely used and have a positioning function. Thus, the user's trajectory can be recorded. In this way, a large amount of personal mobile information can be collected. Tencent location data were obtained on the premise of protecting user privacy. These data were updated every 24 hours, and covered most of the trip routes. Of course, the data also have the disadvantage that unfinished trips over 24 hours were disassembled. These data are mainly displayed by Excel tables, including the starting place, destination, and the number of people traveling by air, train, and car. In order to study the spatial structure of intercity trip networks in China, we selected 346 cities above the prefecture level as the research objects. We used data from 346 cities regarding trips taken by air, train, and road to represent the spatial correlation intensity of Chinese cities from the perspective of aviation, railways, and highways. Other geographic data were obtained from the National Geomatics Center of China. Figure 1 shows the location of major cities in China. Figure 2 shows the population of prefecture-level cities in China.

The Spring Festival travel rush is a unique social and economic phenomenon in China during the transition period. It mainly refers to the high pressure of various traffic modes caused by nationwide, large-scale population migration. The Chinese Spring Festival travel rush is not only a protracted, large-scale population flow, but also has a variety of purposes (e.g., college students and migrant workers return home to visit parents and relatives, and to sightsee). According to an official Chinese report, the floating population was nearly 3 billion during the Spring Festival travel rush in 2018, accounting for one-third of the world's population. Considering the representativeness of the research period and comparisons with similar research, we chose 40-day intercity trip data of Chinese residents during the Spring Festival travel rush as the basis for building the network. The analysis period was from February 1 to March 


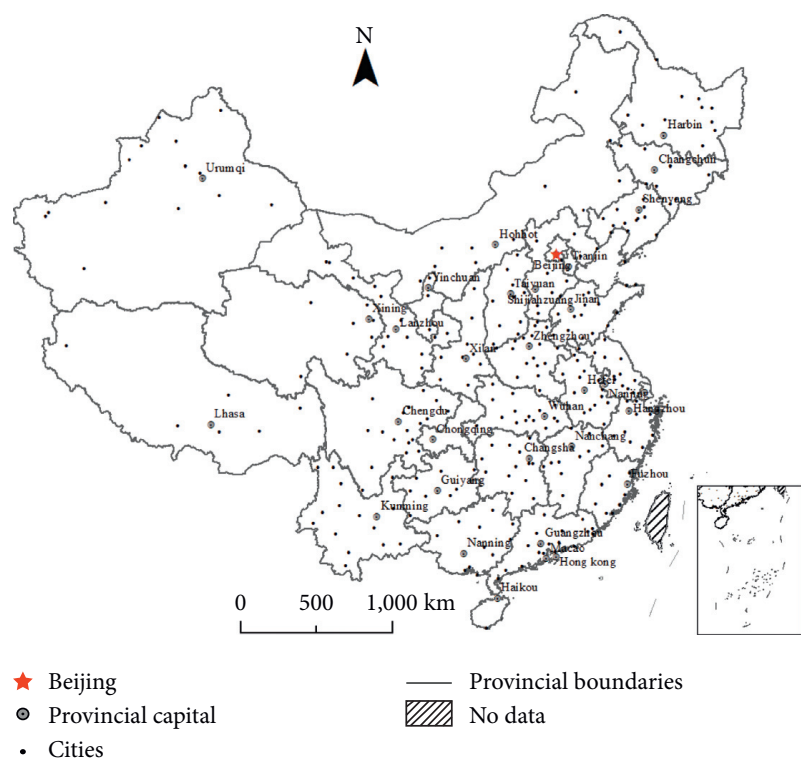

Figure 1: Locations of major cities in China.

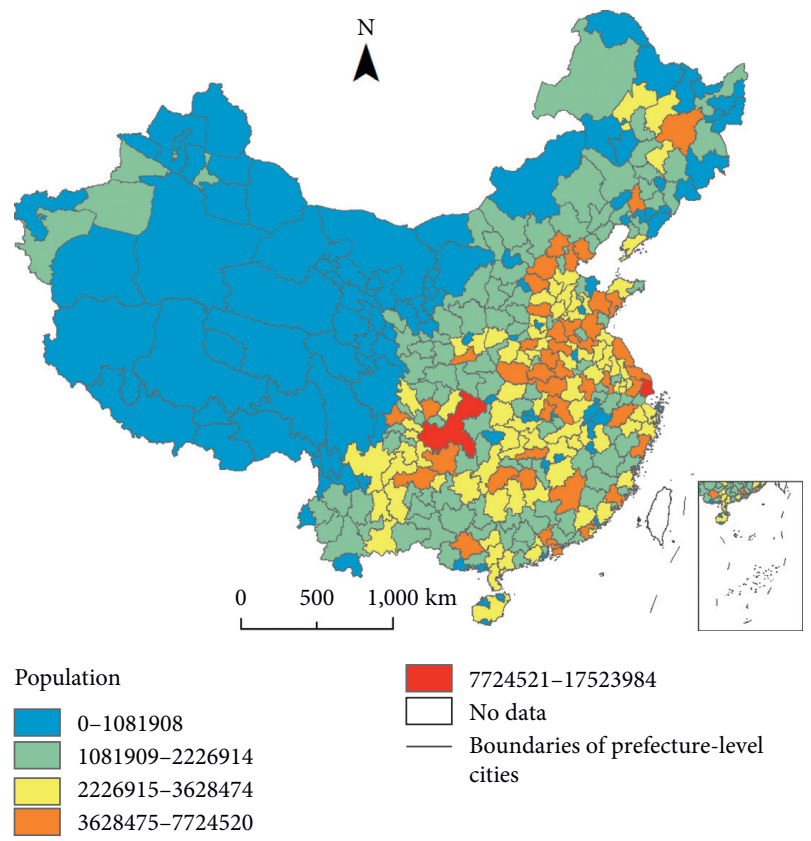

Figure 2: Population of prefecture-level cities in China.

12, 2018. Behind a large number of resident trips is the imbalance between the population and regional economic development. In this study, based on the daily data of population flow during the Spring Festival travel rush in 2018 obtained by Tencent location services, we established the trip relationship network of residents under different travel modes. We analyzed the spatial structure differences of Chinese urban networks under different trip modes, and provided a new perspective for the study of urban network structures. By studying the spatial structure of the intercity trip network of Chinese residents through different travel modes, the multiple spatial characteristics of population migration, resident trips, and urban networks could be revealed from different perspectives. This makes up for the one-sided conclusions drawn from the single-trip mode in the existing research and enriches the regional cognition of the spatial relationship between cities in China.

\section{Results}

4.1. Intercity Trip Pattern of Residents. We used ArcGIS to visualize the population flow routes and intensity under different travel modes. Figure 1 shows how the natural breakpoint classification method was adopted according to railway classification standards. In order to more clearly show the characteristics of the level of population flow, the first-level lines were not shown in the figure. As a whole, the population flow routes under the three travel modes all showed a pattern of sparseness in the west and density in the east. High population flow routes were concentrated in the east side of the "Huhuanyong Line." From the perspective of the China as a whole, there were different degrees of spatial differentiation and spatial dependence in the spatial connection intensity and spatial connection mode of travel in prefecture-level cities, and their hierarchical characteristics interact:

(1) From the perspective of aviation flow (Figure 3(a)), resident travel formed a "diamond" structure with Beijing, Shanghai, Guangzhou-Shenzhen, and Chengdu-Chongqing as the core. The eastern interregional interweaving phenomenon was significant. There are many long-distance routes, and most of them are connected with cities with a developed economic foundation, such as Shanghai-Chongqing, Chongqing-Beijing, Shanghai-Beijing, and Shenzhen-Shanghai. The population flow of these routes is more than 1.89 million people. In addition, there are routes associated with Xi'an, Guiyang, Wuhan, and Nanjing carrying 9.5 million to 1.89 million people, expanding around the "diamond" structure. Southwest, northwest, and northeast of China have fewer aviation routes. Most of them associate between provincial capitals and economically developed cities in the east, and the number of passengers is fewer than 950,000. The three northeastern provinces are closely connected with Beijing. The five provinces of Inner Mongolia, Xinjiang, Tibet, Qinghai, and Gansu have few connecting routes with each other. In the aviation travel network, people are most likely to choose aviation travel when traveling distances between 1,000 and $1,500 \mathrm{~km}$ (Figure 4). It has the characteristics of long distance and short time. The aviation flow clearly reflects the spatial connection and the core-periphery combination at the national scale, which plays a significant role in reflecting the national urban system structure at the macro-scale.

(2) From the perspective of railway flow (Figure 3(b)), in addition to the more obvious "diamond structure," the "three horizontal and one vertical"shaped skeleton inside the diamond was also 

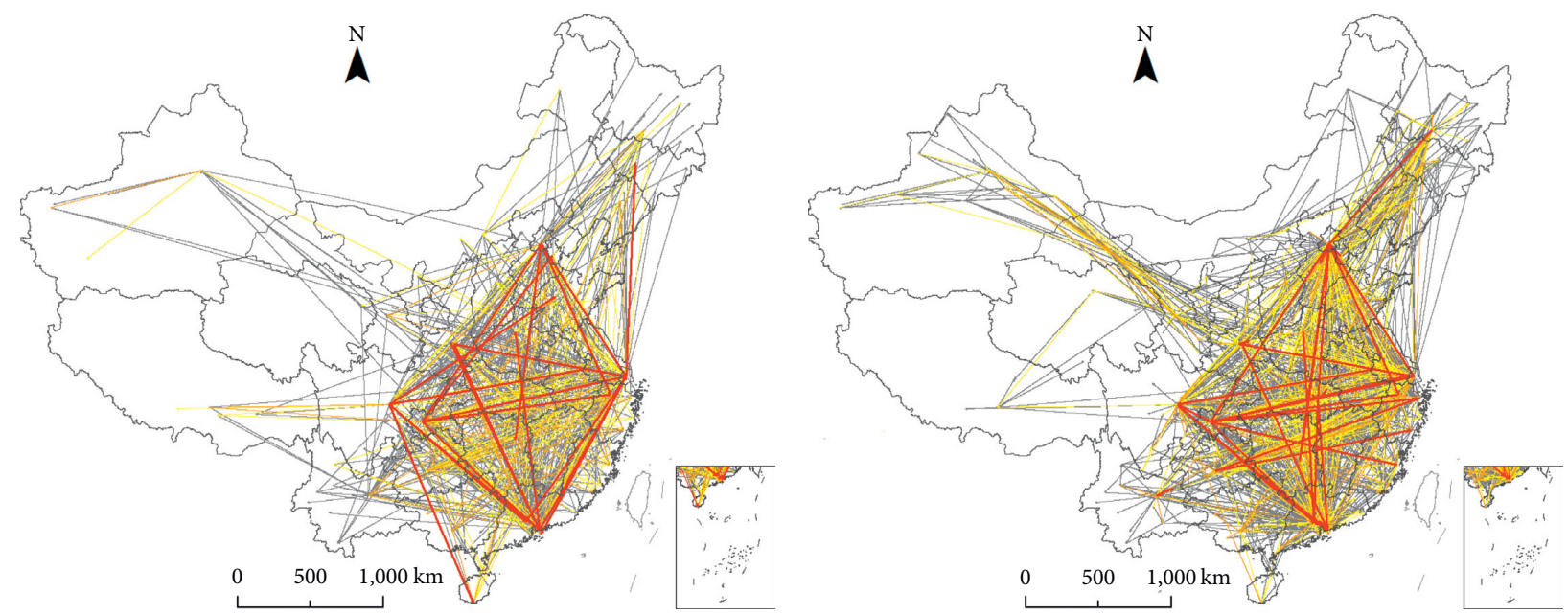

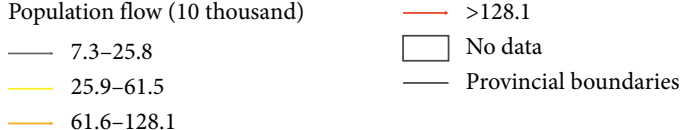

(a)

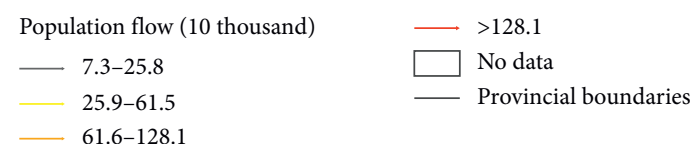

(b)

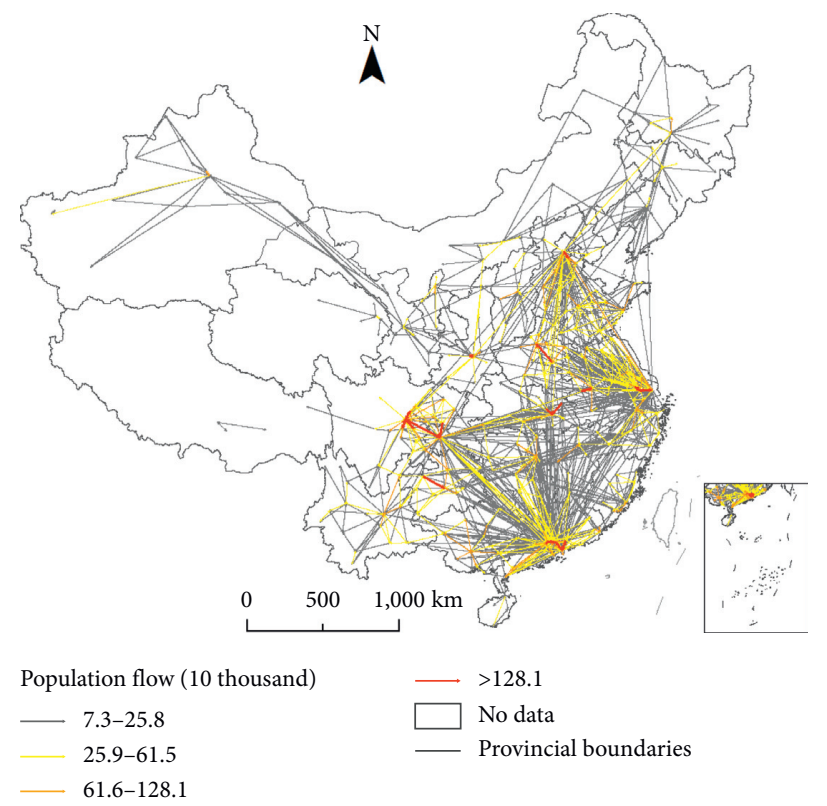

(c)

Figure 3: Routes and intensity of population flow under different travel modes: (a) aviation; (b) rail; (c) highways. The color of the route represents the intensity of population flow, and the change from gray to red represents an increase in the intensity.

relatively clear. The routes at all levels increased, covering a wide range and large density. Among the three modes of travel, the number of trips carried by rail was the largest, accounting for $49 \%$ of the total number of residents traveling in China. When the trip distance was less than $1,500 \mathrm{~km}$, residents chose to travel by rail. Rail travel included long-distance routes like Kashgar to Shanghai, medium- and long-distance routes centered on Beijing, Chengdu, Guiyang, and Zhengzhou, and even short distance routes of only $8 \mathrm{~km}$ between Zhuhai and Macao, which is the most flexible way for residents to travel. The number of railway routes in northwestern and northeastern China is significantly more than that in aviation. Railway flow mainly reflects the travel patterns of residents in the hinterland cities along the national railway arteries, such as BeijingKowloon, Lanzhou-Xinjiang, Beijing-Shanghai, Beijing-Guangzhou, Lanzhou-Lianyungang, Beijing-Harbin, and Beijing-Baotou. The traffic infrastructure plays a significant role in guiding the spatial connections of travel, especially the "alongthe-way effect" of areas covered by high speed rail. 


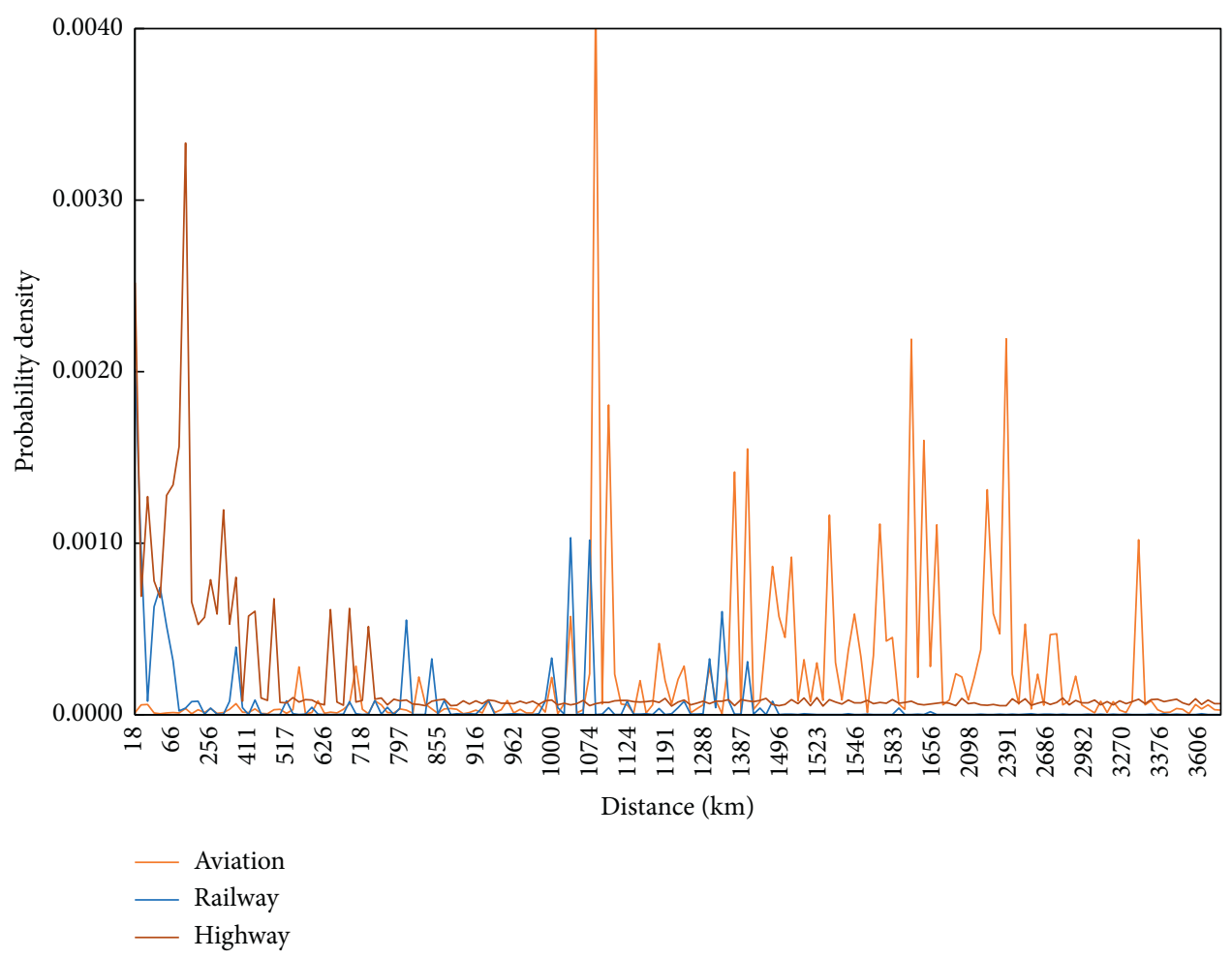

FIgURE 4: Probability distribution of the distance under different travel modes.

(3) From the perspective of highway flow (Figure 3(c)), the distributions of routes and people showed a pattern of outward divergence from the regional central cities. Because the highway is constrained by speed and facilities, the most connected cities are close to cities. When the distance was less than $350 \mathrm{~km}$, the highway was the preferred mode of travel. Among them, the number of routes carrying 7.32-25.78 million people was the largest, reaching 1642 , while there were only 32 routes with more than 1.812 million people. In comparison, the western route was longer, and the eastern route was shorter. Highway flows mainly reflected the spatial dependence and core-peripheral combination of travel on the inner levels of urban agglomerations. This clearly showed the development of each urban agglomeration. The Beijing-Tianjin-Hebei urban agglomeration, Yangtze River Delta, Pearl River Delta, Chengdu-Chongqing urban agglomeration, and the Central Plains urban agglomerations had hierarchical relationships. The hierarchical relationships of the urban agglomerations of Harbin-Changchun, Shandong Peninsula, Guanzhong Plain, Wuhan, and the Beibu Gulf had already appeared, while the remaining urban agglomerations were weak.

In order to compare the population distribution scale of different travel modes in each city, we drew a scatter plot. In the scatter plot, the points represent cities, the $x$-axis and $y$ - axis represent highways and railways, respectively, and the color represents aviation (Figure 5). The results showed the following characteristics of resident travel: from the perspective of distribution scale, Shanghai, Beijing, Guangzhou, Chongqing, Shenzhen, and Chengdu were all in the forefront in the three travel modes. These six cities are national trip distribution centers. Under the three travel modes, the cities with a low value of the distribution scale accounted for the majority, while the number of cities in medium- and high-value areas was small. From the perspective of trip routes (Table 1), during the Spring Festival travel rush, the total number of passengers carried by aviation was 395.906 million people, and the top 10 routes carried $10 \%$ of these passengers. The cities connected by these routes were exactly at the four apexes of the "diamond"-shaped structure. Trains carried the largest number of passengers during the Spring Festival travel rush, up to 1151.46 million people. Among the top 10 routes, except Wuhan, which is the central point of the internal cross-skeleton crossing the "diamond" shape, the "diamond"-shaped structure was still in the center of the route, but the top 10 routes only accounted for $2.6 \%$ of the total. During the Spring Festival travel rush, 802.237 million people chose highways as their travel mode. The top 10 routes exactly represented the close connections between the core cities and sub-core cities in the three urban agglomerations of Beijing-Tianjin-Hebei (Beijing and Langfang), the Yangtze River Delta (Shanghai and Suzhou), and the Pearl River Delta (Shenzhen, Dongguan, Huizhou, Guangzhou, and Foshan). The two-way routes of Xi'an and 


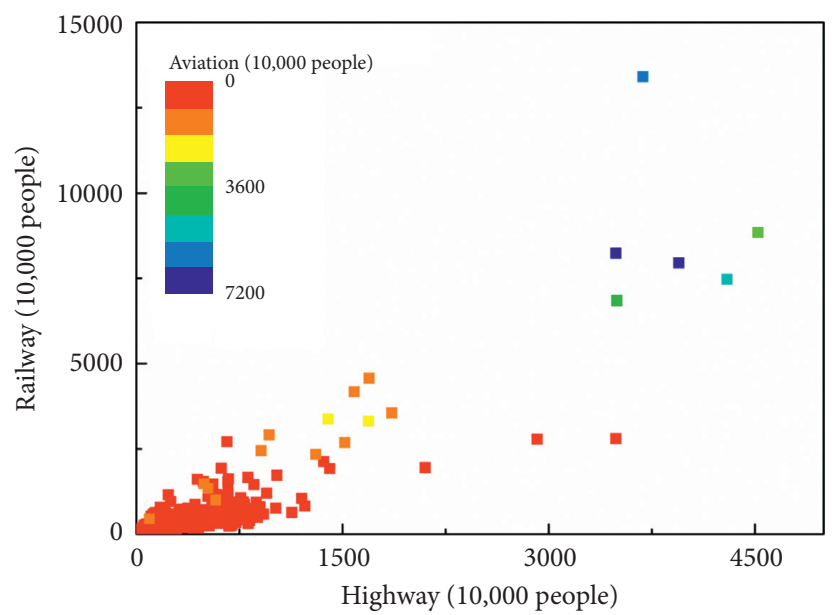

Figure 5: Population distribution scale under different travel modes.

TABle 1: Top 10 population flow routes and populations under different travel modes.

\begin{tabular}{|c|c|c|}
\hline $\begin{array}{l}\text { Travel } \\
\text { mode }\end{array}$ & Top 10 flow routes and populations (10,000 people) & Proportion \\
\hline Aviation & $\begin{array}{l}\text { From Shanghai to Chongqing (561.97), from Chongqing to Shanghai } \\
\text { (561.79), from Chongqing to Beijing (531.66), from Beijing to Chongqing } \\
\text { (495.89), from Shenzhen to Chengdu (391.39), from Chengdu to Shenzhen } \\
\text { (353.64), from Shanghai to Beijing (335.05), from Beijing to Shanghai } \\
\text { (330.75), from Shenzhen to Shanghai (326.07), and from Guangzhou to } \\
\text { Shanghai (286.53). }\end{array}$ & $\begin{array}{c}\text { A total of } 41.7476 \text { million people, accounting for } \\
10.54 \% \text { of the total carrying capacity. }\end{array}$ \\
\hline Railway & $\begin{array}{c}\text { From Shanghai to Chongqing (398.96), from Chongqing to Shanghai } \\
\text { (384.79), from Foshan to Guangzhou (309.32), from Guangzhou to } \\
\text { Foshan (307.67), from Chongqing to Beijing (296.40), from Changsha to } \\
\text { Beijing (296.39), from Beijing to Chongqing (260.11), from Wuhan to } \\
\text { Beijing (246.53), from Beijing to Shanghai (244.27), and from Chengdu to } \\
\text { Nanjing (238.58). }\end{array}$ & $\begin{array}{c}\text { A total of } 29.8301 \text { million people, accounting for } \\
2.60 \% \text { of the total carrying capacity. }\end{array}$ \\
\hline Highway & $\begin{array}{l}\text { From Shenzhen to Dongguan (377.45), from Dongguan to Shenzhen } \\
\text { (374.35), from Shanghai to Suzhou (270.93), from Suzhou to Shanghai } \\
\text { (263.99), from Foshan to Guangzhou (256.25), from Guangzhou to } \\
\text { Foshan (250.17), from Xianyang to Xi'an (203.18), from Beijing to } \\
\text { Langfang (202.05), from Xi'an to Xianyang (201.19), and from Shenzhen to } \\
\text { Huizhou (188.14). }\end{array}$ & $\begin{array}{c}\text { A total of } 25.8772 \text { million people, accounting for } \\
3.23 \% \text { of the total carrying capacity. }\end{array}$ \\
\hline
\end{tabular}

Xianyang of the Guanzhong urban agglomeration in the west entered the top 10, while the population flow between Chengdu and Chongqing of the largest urban agglomeration in the west did not enter the top 10 in China under the three travel modes. This deserves further attention.

Figure 6 shows the distribution scale and type of population flow under different travel modes (where the natural breakpoint classification method is adopted according to the railway classification standard). The distribution scale of a city is the sum of the inflow and outflow population, which represents the capacity of a city to receive tourists. From the distribution scale, it can be seen that there were four and six cities in the highest distribution level (>45.674 million people) in aviation and railway, respectively. There was no city in the first level in the highway mode. In the second level (17.187-45.674 million people), the numbers of cities in aviation, railway, and highway were 4,16 , and 10, respectively. In the third level (5.544-17.187 million people), there were 21 cities under the aviation mode. Most were distributed in the eastern region, and most of them were provincial capitals. There were 81 cities on the railway, mainly distributed along the railway route. There were 85 cities on the highway, concentrated in the eastern region and distributed in blocks. In contrast, the spatial differentiation of the intercity population based on aviation trips was the most obvious. It was characterized by high polarization and discrete point embedding, reflecting a core-periphery structure with national hub cities as the core distribution. The pattern of intercity population flow based on railway trips basically showed a core-periphery structure that used the cities along the national railway aorta as the core, and gradually decreased to the hinterland cities. The intercity population flow based on highway travel was a spatial pattern with strong local aggregation that matched the 


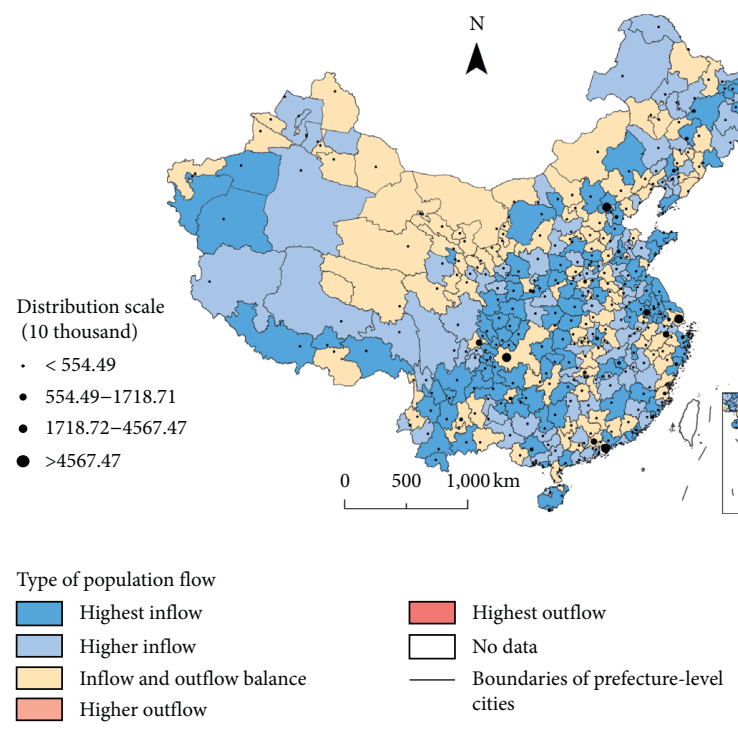

(a)
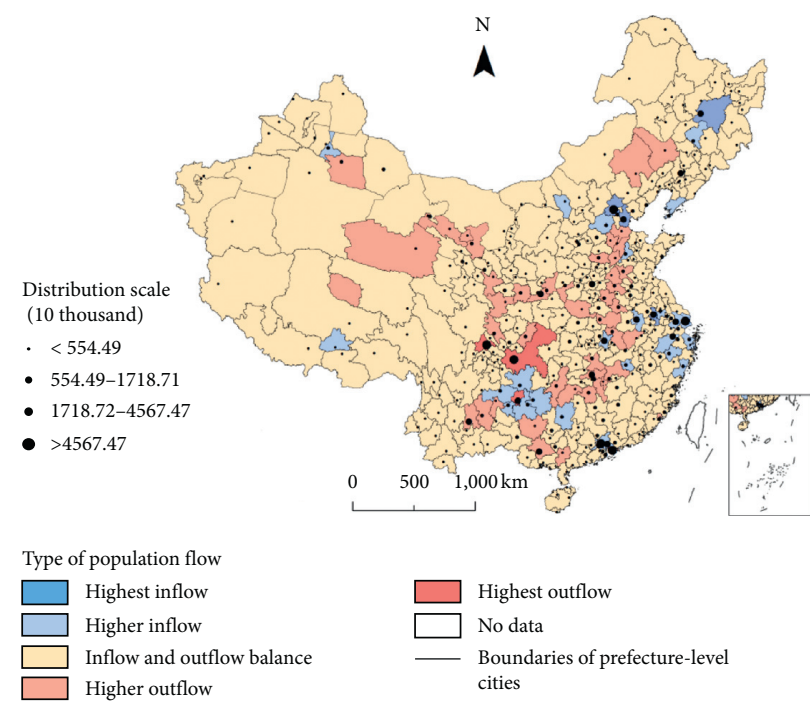

(b)

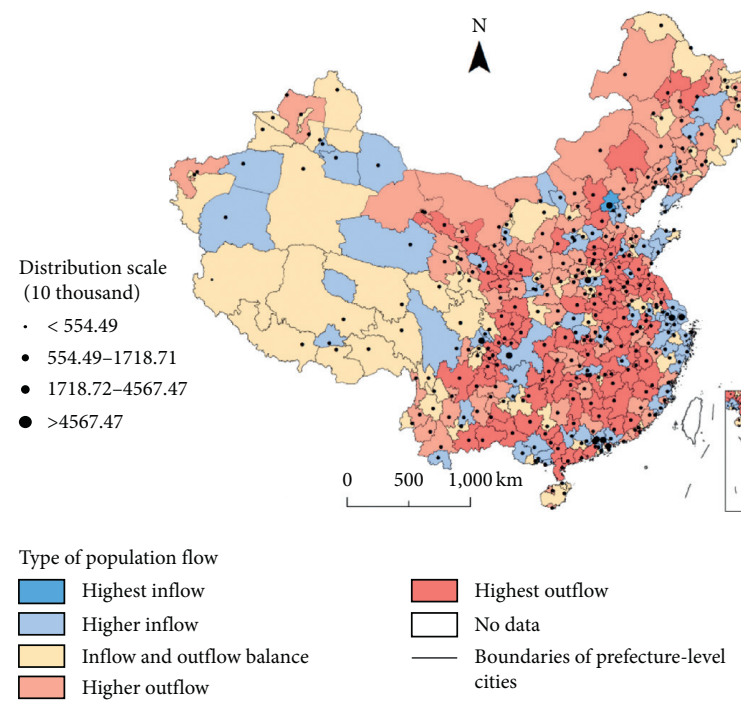

(c)

Figure 6: Distribution scale and type of population flow under different travel modes: (a) aviation; (b) rail; and (c) highway. Map spots of different colors show the different types of population flow, and the points represent the distribution scale. The larger the point, the stronger the distribution capacity of the cities.

population scale. It formed three strong aggregation regions in space: Beijing-Tianjin-Hebei-Yangtze River Delta-Central Plains, the Sichuan Basin, and the Pearl River Delta.

The type of population flow was obtained by subtracting the inflow population from the outflow population of the city. The gap between the outflow population and the inflow population was displayed, so as to judge the urban population flow direction. Different travel modes presented different types of urban inflow and outflow (Figure 6). (1) In terms of aviation travel (Figure 6(a)), there were 118 cities with the highest population inflow, among which cities with a net inflow of more than 300,000 include Nanjing, Tianjin, Jinan, Nanchang, Wuhan, Hong Kong, Changchun, and other major regional center cities, as well as Sanya, Bijie, Guilin, Lijiang, Nyingchi, and other tourist cities. The cities with the highest population outflow were Shenzhen, Chongqing, Chengdu, Guiyang, Guangzhou, Hangzhou, etc. Except for Xianyang, the cities with a net outflow population of 300,000 or more were all provincial capitals and above. On the whole, the number of cities with net population inflow was large, while the number of cities with net population outflow was relatively small. (2) In terms of railway travel (Figure 6(b)), the highest population inflow cities were only Beijing and Nanjing. The higher population outflow cities, higher population inflow cities, cities with equal inflow and outflow, and highest population outflow cities were crossdistributed. Among them, the highest population outflow cities were Chongqing, Guiyang, Kunming, Shenzhen, etc. The higher population outflow cities and the higher population inflow cities had the same number. Of the 16 cities 
with a net outflow population of more than 600,000 , nine cities were located in the western region. Of the 23 cities with a net inflow population of more than 600,000, only Urumqi and Qiannan Prefecture were western cities. (3) In terms of highway travel (Figure 6(c)), cities with equal inflow and outflow were mostly distributed in the northwest and northeast regions, and the number of outflow cities was more than that of inflow cities. The cities with the largest population outflow (over 400,000) were Zhoukou, Shaoyang, Shangrao, Ganzhou, Yichun, Yulin, Handan, Huaihua, and Zhaotong, all of which were major laborexport cities in central and western China. Chongqing had a higher population inflow under the highway travel mode. From February 1 to February 14, the number of people entering Chongqing every day was twice that at other times. On February 11 alone, the population of Chongqing reached 761,800 by highway, while on March 1, only 250,000 people entered Chongqing, and the number of inflow routes was shortened from 163 to 102 . However, in terms of comprehensive aviation and railway, Chongqing's output of passengers during the Spring Festival transportation was far more than that by highway. Indeed, Chongqing is generally a highly populated outflow city. The scale of urban inflow and outflow was different under different travel modes. This was mainly determined by the city grade and location. The inflow and outflow of high-grade cities such as Beijing and Shanghai were not significantly different, while those of Qingyang and Wuwei were mostly larger than the inflow.

Figure 7 shows the intercity trip network structure under the maximum dominant flow. From the point of view of dominant flow routes, the maximum dominant flow routes of aviation, railway, and highways presented a spatial distribution pattern from long to short, and from complex to simple. The rhombus structure network framework supported by the cross was prominent in the dominant aviation flow (Figure 7(a)). It undertook the function of long-distance transportation, was little influenced by the constraints of geographical space, and had the network characteristics of a "hyperplane." Moreover, the maximum dominant flow of aviation was directly associated with first-tier cities in the different regions of China, and had the function of building the main network framework at a national and even global level, as the main form of framework construction of China's urban association pattern. The maximum dominant flow of railway mostly presented a typical pole axis spatial system pattern (Figure 7(b)). The railway mainly undertook the function of medium- and long-distance transportation. At the macro-level, it served as an important axis belt for a national development strategy. It directly associated and drove the element flow within large regions, and promoted the development of cities along the line to form an economic axis belt. On the other hand, it provided a support axis belt that connected central cities to the core framework. The maximum dominant flow of highways was a star-shaped divergent radiation pattern (Figure 7(c)), which effectively filled in for the whole traffic skeleton and the supporting axis belt. The highway mainly undertook the function of shortdistance transportation. Due to the influence of regional divisions caused by the administrative forces of different provinces, highway trips were mostly limited to administrative units within provinces or nearby provinces and regions. The "localization" feature was significant, reflecting the internal connections of the relatively complete regional system. The urban network coverage areas covered by the three maximum dominant flows of aviation, railway, and highways overlapped, but each had its own emphasis. They respectively depicted the network characteristics of the national, regional, and provincial spatial scales, forming interregional interdependence, indispensable element association, and a spatial relationship.

From the number of cities associated with the maximum dominant flow route, we could see that Beijing and Shanghai were associated with 69 and 70 cities, respectively, under the maximum dominant flow of aviation (Figure 7(a)), occupying a dominant position. Shenzhen, Chengdu, and Chongqing were respectively associated with 36,36 , and 27 cities with the maximum dominant flow, which are in the second level. Guangzhou, Urumqi, Wuhan, Kunming, Harbin, Xi'an, and Changsha had more than five related cities. In the maximum dominant flow of the railway (Figure 7(b)), Beijing and Chengdu were all associated with 21 cities of the maximum dominant flow, which was far less than the number of cities associated with the first level of the aviation maximum dominant flow. There were 11 cities, such as Wuhan, Urumqi, Zhengzhou, and Guangzhou, with more than 10 related cities. Chengdu ranked first in the maximum dominant flow of highways (Figure 7(c)), which was related to 15 cities, followed by Zhengzhou, Guangzhou, Xi'an, and Changsha. Among the top 30 cities, except Foshan and Dongguan, were all provincial capitals and above. In the maximum dominant flow, the more dominant flow routes connected by the city, the higher the dependence of that city.

\subsection{Structural Characteristics of the Urban Trip Network}

4.2.1. Alter-Based Centrality and Alter-Based Power. The calculation results regarding the alter-based centrality (AC) and alter-based power (AP) (Table 2) showed the following. Beijing, Shanghai, Chongqing, Guangzhou, Shenzhen, and Chengdu ranked in the top 10 in all three travel modes. As far as the aviation mode was concerned, Chongqing had the strongest centrality. Shanghai had the strongest alter-based power, which proved that Shanghai had the largest dominance and influence in the entire aviation passenger transportation network. As far as the railway mode was concerned, Beijing had the greatest alter-based centrality and alter-based power. In the railway passenger network, Beijing had an absolute advantage as a national administrative center. It not only connected many routes and had a wide range but also had a strong influence on the routes it connected. As far as the highway mode was concerned, Shenzhen had the highest alter-based centrality. Its highway transportation network was very dense, and migrant workers from the south often traveled in Shenzhen. In addition, Shenzhen was directly connected to Shanghai, Chengdu, Beijing, and other cities through a number of highway routes. It can be said that the distribution capacity 

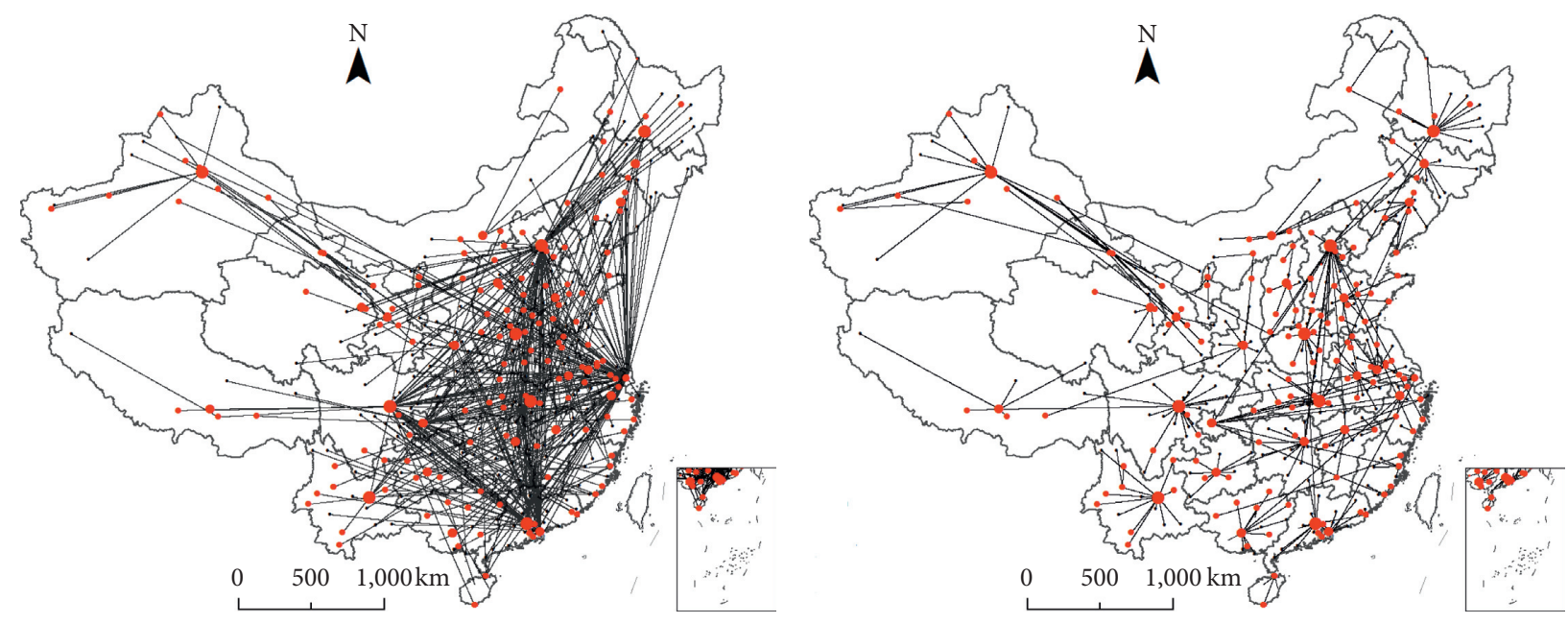

Number of connected cities

Number of connected cities

- 1-4

- $1-4$

- $4-11$

- 4-11

- $>11$

(a)

(b)

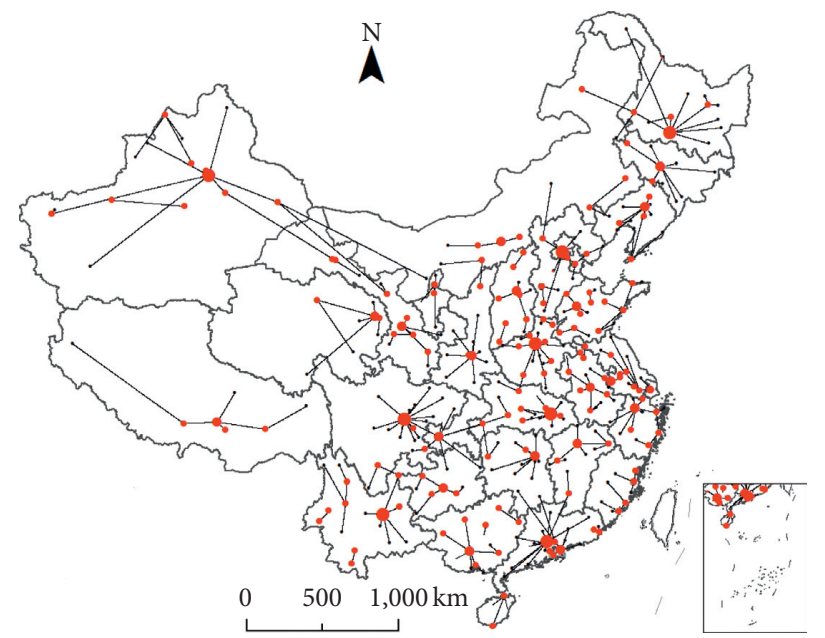

Number of connected cities

- 1-4

- 4-11

- $>11$

(c)

FiguRE 7: Characteristics of urban-trip association based on the maximum dominant flow under different travel modes: (a) aviation; (b) railway; (c) highway.

TABle 2: Top 10 and bottom 10 cities of alter-based centrality (AC) and alter-based power (AP) under different trip modes.

\begin{tabular}{|c|c|c|c|c|c|c|c|c|c|}
\hline \multirow{2}{*}{ Rank order } & \multirow{2}{*}{ Cities } & \multicolumn{2}{|c|}{ Aviation } & \multirow{2}{*}{ Cities } & \multicolumn{2}{|c|}{ Railway } & \multirow{2}{*}{ Cities } & \multicolumn{2}{|c|}{ Highway } \\
\hline & & $\mathrm{AC}$ & $\mathrm{AP}$ & & $\mathrm{AC}$ & $\mathrm{AP}$ & & $\mathrm{AC}$ & $\mathrm{AP}$ \\
\hline 1 & Chongqing & 1 & 0.808 & Beijing & 1 & 1 & Shenzhen & 1 & 0.932 \\
\hline 2 & Shanghai & 0.938 & 1 & Chongqing & 0.941 & 0.481 & Guangzhou & 0.977 & 0.951 \\
\hline 3 & Beijing & 0.656 & 0.778 & Shanghai & 0.801 & 0.559 & Dongguan & 0.96 & 0.644 \\
\hline 4 & Shenzhen & 0.63 & 0.716 & Guangzhou & 0.72 & 0.643 & Chongqing & 0.812 & 0.891 \\
\hline 5 & Guangzhou & 0.464 & 0.545 & Shenzhen & 0.645 & 0.564 & Shanghai & 0.774 & 0.733 \\
\hline 6 & Chengdu & 0.443 & 0.741 & Chengdu & 0.633 & 0.564 & Suzhou & 0.717 & 0.68 \\
\hline 7 & Hangzhou & 0.27 & 0.261 & Wuhan & 0.486 & 0.286 & Beijing & 0.697 & 0.856 \\
\hline
\end{tabular}


TABLE 2: Continued.

\begin{tabular}{|c|c|c|c|c|c|c|c|c|c|}
\hline \multirow{2}{*}{ Rank order } & \multirow{2}{*}{ Cities } & \multicolumn{2}{|c|}{ Aviation } & \multirow{2}{*}{ Cities } & \multicolumn{2}{|c|}{ Railway } & \multirow{2}{*}{ Cities } & \multicolumn{2}{|c|}{ Highway } \\
\hline & & $\mathrm{AC}$ & $\mathrm{AP}$ & & $\mathrm{AC}$ & $\mathrm{AP}$ & & $\mathrm{AC}$ & $\mathrm{AP}$ \\
\hline 8 & Xi'an & 0.241 & 0.118 & Xi'an & 0.441 & 0.273 & Chengdu & 0.597 & 1 \\
\hline 9 & Nanjing & 0.203 & 0.163 & Zhengzhou & 0.329 & 0.261 & Foshan & 0.566 & 0.39 \\
\hline 10 & Xianyang & 0.185 & 0.085 & Hangzhou & 0.324 & 0.209 & Huizhou & 0.419 & 0.155 \\
\hline$\ldots$ & $\ldots$ & $\ldots$ & $\ldots$ & $\ldots$ & ... & $\ldots$ & $\cdots$ & & $\ldots$ \\
\hline 337 & Huaibei & 0 & 0 & Daxinganling & 0.001 & 0.002 & Guoluo & 0.002 & 0.006 \\
\hline 338 & Chenzhou & 0 & 0 & Kezhou & 0.001 & 0.004 & Shannan & 0.002 & 0.004 \\
\hline 339 & Yushuzhou & 0 & 0 & Nujiang & 0.001 & 0.001 & Yushuzhou & 0.002 & 0.005 \\
\hline 340 & Yunfu & 0 & 0 & Hetian & 0.001 & 0.002 & Aletai & 0.002 & 0.011 \\
\hline 341 & Shaoguan & 0 & 0 & Huangnanzhou & 0.001 & 0.001 & Qionghai & 0.002 & 0.017 \\
\hline 342 & Hezhou & 0 & 0 & Shennongjia & 0.001 & 0.001 & Kezhou & 0.002 & 0.013 \\
\hline 343 & Bozhou & 0 & 0 & Changdu & 0.001 & 0 & Daxinganling & 0.001 & 0.002 \\
\hline 344 & Shennongjia & 0 & 0 & Aletai & 0 & 0.001 & $\mathrm{Naqu}$ & 0.001 & 0.003 \\
\hline 345 & Guoluo & 0 & 0 & Guoluo & 0 & 0.001 & Rikaze & 0.001 & 0.005 \\
\hline 346 & Wuzhou & 0 & 0 & Ali & 0 & 0 & Ali & 0 & 0.002 \\
\hline
\end{tabular}

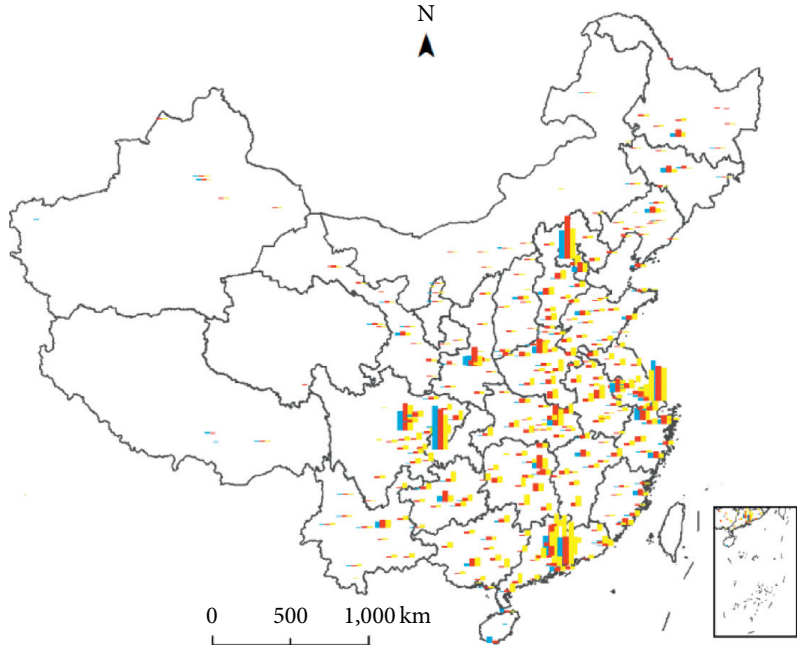

Alter-based centrality

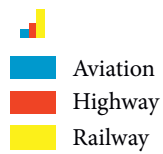

FIGURE 8: Classification of alter-based centrality under different travel modes.

was very strong. In terms of alter-based power, Chengdu occupied first place. In the road network, Chengdu was in the middle of the network. The city served as an important carrier of communication between the east and the west, and occupied an important position in the highway network.

We used ArcGIS software to visualize the data (Figure 8). Under different travel modes, city hierarchies are presented by $\mathrm{AC}$ values as a pyramid. That is, the $\mathrm{AC}$ value was high and the number of cities was small. In aviation mode, the hierarchical structure was the most clear: the number of high-level cities was the smallest and they were scattered, e.g., Shanghai, Chongqing, and Shenzhen. As a high end way of traveling, aviation has a high demand on the site cost. Only cities with strong collection and distribution capacities could support them, and the number was small. In highway

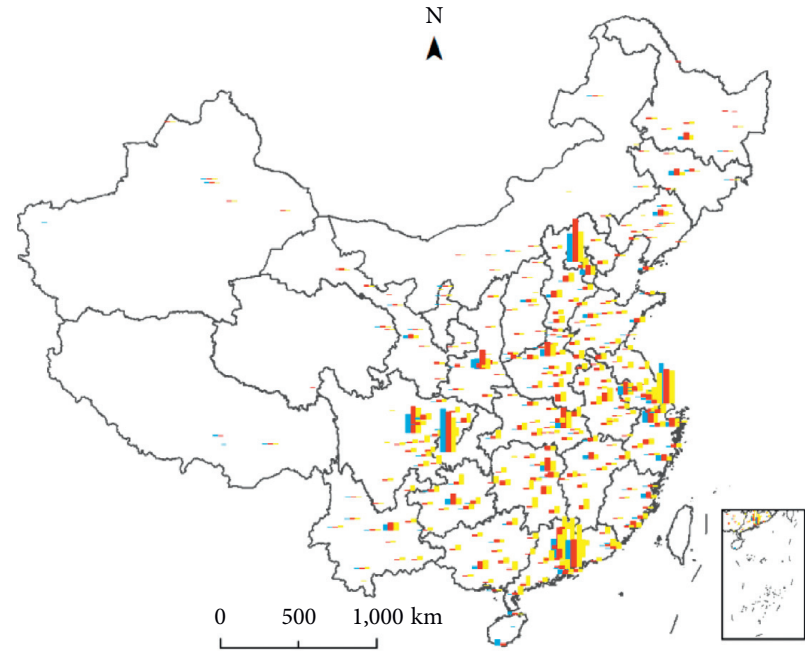

Alter-based power

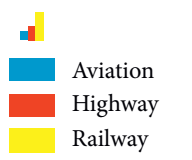

FIgURE 9: Classification of alter-based power under different travel modes.

mode, the number of high-level cities increased significantly. The highway service distance was short, the number of people traveling on highways was small, and most were concentrated in the surrounding cities. Therefore, the embodiment of the distribution capacity was mostly connected with the surrounding cities, and the gap between the cities was small. In railway mode, the number of high-level cities in terms of their AC values fell between those of highways and aviation. Railways had a wide range of services, they connected many cities, and the hierarchical structure of the AC was between aviation and highways.

Figure 9 shows the AP map under different travel modes of the Spring Festival travel. In aviation, six cities (viz., Shanghai, Chongqing, Beijing, Chengdu, Shenzhen, and Guangzhou) were at the highest level. They had strong 
control over the connected routes and surrounding cities. On railways, the lowest-level cities were in Tibet, Qinghai, Inner Mongolia, and Hainan. Other provinces appear with high AP-value cities. On highways, Suzhou, Zhengzhou, Foshan, Xi'an, Dongguan, Kunming, Nanjing, Nanning, and Hangzhou were added to the highest level (0.287-1). As a whole, the distribution of cities with high alter-based power was relatively balanced. Unlike cities with a high alter-based centrality, Yinchuan, Lanzhou, Urumqi, Xining, and other cities were the hub nodes for population flow from west to east, and the AP value was significantly higher than the AC value. These results confirmed that the intermediary and distribution functions of some cities in the process of population flow could be better reflected by alter-based power.

When analyzing urban networks, the alter-based centrality and alter-based power jointly determined the status of a city. Generally speaking, there was a positive correlation between the city's AC and AP values. That is to say, a city with a high AC value had a high AP value, and a city with a strong ability to gather and spread resources had a stronger ability to control those resources. Of course, there were differences in some cities. Neal, by measuring the world urban information network, divided quintessential cities with high centrality and high power, hub cities with high centrality and low power, and gateway cities with low centrality and high power [22]. Thus, we could better identify the status and attributes of cities [39]. The natural breakpoint classification method was used to classify the alter-based centrality and alter-based power of the aviation network (Table 3), and the city type was divided based on the matching relationship between cities at different levels. The ratio of the number of cities at the first level, second level, third level, and other levels was 5:8:24:309, and the ratio of the number of quintessential, hub, gateway, and edge cities was $23: 7: 7: 309$.

Using the same method to divide the urban hierarchy structure of the railway network, the ratio of the number of cities at the first level, second level, third level, and other levels was $6: 16: 63: 261$. The ratio of the number of quintessential, hub, gateway, and edge cities was $33: 37: 15: 261$. Compared with aviation travel, the number of other-level edge cities decreased significantly, and the number of quintessential cities increased.

From the perspective of gateway cities, most second-level cities were provincial capital cities with relatively good geographic locations. There were only eight gateway cities at the third level. Based on the statistics of the urban hierarchical structure of the highway trip network, we found that the ratio of the number of cities at the first level, second level, third level, and other levels was $8: 49: 118: 171$. The ratio of the number of quintessential, hub, gateway, and edge cities was $73: 80: 22: 171$. The number of quintessential cities and hub cities increased significantly. The number of third-level quintessential cities was the largest, and the number of gateway cities was less. In view of the three types of trip networks, the same city has different hierarchical structures in different trip networks. For example, Tianjin is classified as a quintessential city at the third level in the aviation network; in the railway network, it is a gateway city at the second level; and in the highway network, it is a hub city at the second level. As a whole, the number of gateway cities changed less. With the trip mode from aviation to railway to highway, the number of edge cities decreased and the number of third-level cities increased.

4.2.2. Cluster Structure of Urban Trip Network. The network cluster structure refers to a complex system in which clusters are interconnected with other clusters according to certain rules. A network with a clustered structure features a high average clustering coefficient. That is, the higher the average clustering coefficient, the more obvious the clustered structure [3]. In this study, we used the fast-unfolding clustering algorithm to divide the city types under different travel modes during the China Spring Festival rush, so as to obtain small groups with close internal connections and relatively few regional connections. The principle of fast-unfolding clustering is to repeatedly divide through iterative operations, so that the overall modularity of the divided network continues to increase until the network structure no longer changes [49]. Cluster analysis in Gephi software needs to ensure that the value of the modularity reaches the maximum. The greater the modularity value, the better the cluster structure division effect [50]. The statistical table for the urban cluster structure under different travel modes during the Spring Festival rush was obtained through calculation (Table 4). The number of clusters divided under different travel modes was different. The number of urban clusters was the least in aviation mode, at only seven. The difference in the number of cities included in each cluster structure was also the largest. For example, cluster 0 contained the largest number of cities, reaching 113 , while cluster 4 and cluster 6 contained only two cities. There were eight clusters divided by railway mode, and the gap in the number of cities included in each cluster also narrowed. The number of clusters was the most under highway mode, with 10 clusters, and the number of cities in each cluster was the most balanced.

A spatial visualization of the cluster structure under different travel modes is shown in Figure 10. The cluster structure of different travel modes was obviously different, among which the average clustering coefficient value was represented as aviation < railway<highway. The cluster structure was the most significant in highway mode, and the aviation cluster structure was relatively weak. Under aviation, it was characterized by fewer categories, discontinuous clusters, a large spatial span, fewer geographical constraints, and a jump distribution. The cluster structure under railway mode had an aggregation state and high spatial connectivity, but there were also discontinuous jump clusters, such as cluster 2 (Jiangsu, Anhui, Zhejiang, Jiangxi, Chongqing, and Guizhou). The cluster structure under highway mode appeared as a block distribution. This was similar to the cluster structure of the railway in general, although the coincidence degree between the cluster boundary and the provincial boundary was higher. In conclusion, due to the limitation of geographical spatial effect, adjacent cities are more likely to form a cluster. Some clusters from the 
TABLE 3: City hierarchy in the aviation network.

\begin{tabular}{|c|c|c|c|c|}
\hline Level & Types & $\begin{array}{c}\text { Alter-based } \\
\text { centrality }\end{array}$ & $\begin{array}{l}\text { Alter-based } \\
\text { power }\end{array}$ & Cities included (and cities number) \\
\hline $\begin{array}{l}\text { Nationwide } \\
\text { level }\end{array}$ & $\begin{array}{l}\text { Quintessential world } \\
\text { cities }\end{array}$ & $0.464-1.000$ & $0.261-1.000$ & $\begin{array}{l}\text { Chongqing, Shanghai, Beijing, Shenzhen, Guangzhou } \\
\text { (5) }\end{array}$ \\
\hline \multirow{3}{*}{ Regional level } & $\begin{array}{l}\text { Quintessential world } \\
\text { cities }\end{array}$ & $0.203-0.463$ & $0.118-0.260$ & Chengdu, Hangzhou, Nanjing (3) \\
\hline & Hub world cities & $0.203-0.463$ & $0-0.117$ & Xi'an (1) \\
\hline & Gateway world cities & $0-0.202$ & $0.118-0.260$ & Wuhan, Zhengzhou, Kunming, Guiyang (4) \\
\hline \multirow{3}{*}{ Local level } & $\begin{array}{l}\text { Quintessential world } \\
\text { cities }\end{array}$ & $0.056-0.202$ & $0.034-0.117$ & $\begin{array}{c}\text { Xianyang, Tianjin, Changsha, Wenzhou, Jinan, } \\
\text { Lanzhou, etc. (15) }\end{array}$ \\
\hline & Hub world cities & $0.056-0.202$ & $0-0.033$ & $\begin{array}{c}\text { Changchun, Hongkong, Zhuhai, Hefei, Shijiazhuang, } \\
\text { Taiyuan (6) }\end{array}$ \\
\hline & Gateway world cities & $0-0.055$ & $0.034-0.117$ & Urumqi, Qingdao, Hohhot (3) \\
\hline Other level & Edge cities & $0-0.055$ & $0-0.033$ & $\begin{array}{l}\text { Dalian, Foshan, Yinchuan, Guilin, Yangzhou, Ili, etc. } \\
\text { (309) }\end{array}$ \\
\hline
\end{tabular}

TABLE 4: Statistical table of urban cluster structure and number of cities under different trip modes.

\begin{tabular}{|c|c|c|c|c|c|}
\hline \multicolumn{2}{|c|}{ Aviation } & \multicolumn{2}{|c|}{ Railway } & \multicolumn{2}{|c|}{ Highway } \\
\hline Cluster type & Number of cities & Cluster type & Number of cities & Cluster type & Number of cities \\
\hline 0 & 113 & 0 & 77 & 0 & 56 \\
\hline 1 & 44 & 1 & 84 & 1 & 62 \\
\hline 2 & 98 & 2 & 63 & 2 & 62 \\
\hline 3 & 72 & 3 & 18 & 3 & 28 \\
\hline 4 & 2 & 4 & 8 & 4 & 29 \\
\hline 5 & 15 & 5 & 11 & 5 & 16 \\
\hline \multirow[t]{4}{*}{6} & 2 & 6 & 53 & 6 & 18 \\
\hline & & 7 & 32 & 7 & 27 \\
\hline & & & & 8 & 31 \\
\hline & & & & 9 & 17 \\
\hline
\end{tabular}

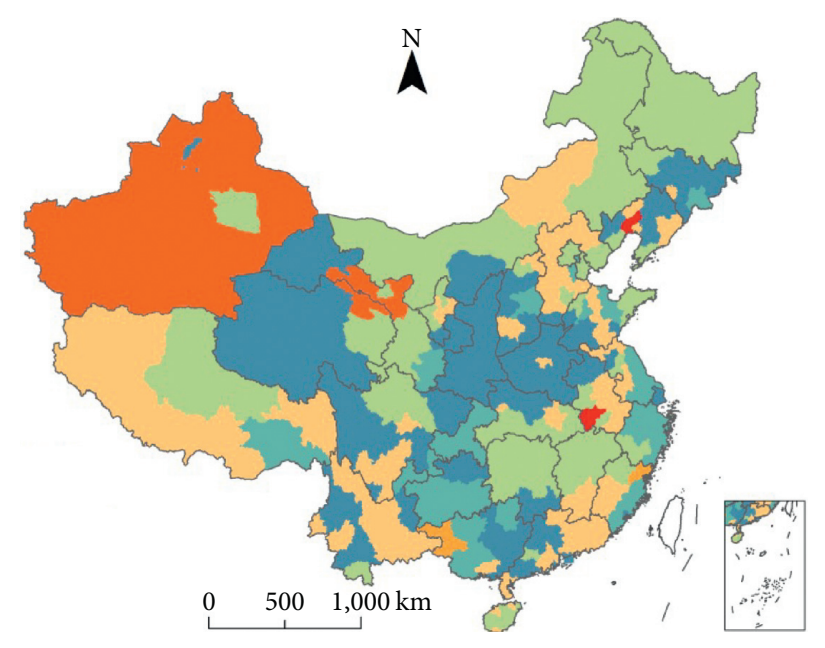

Cluster structure

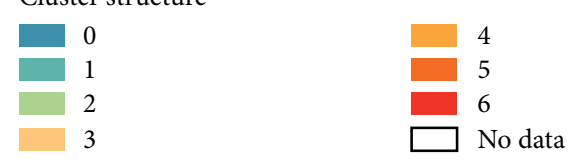

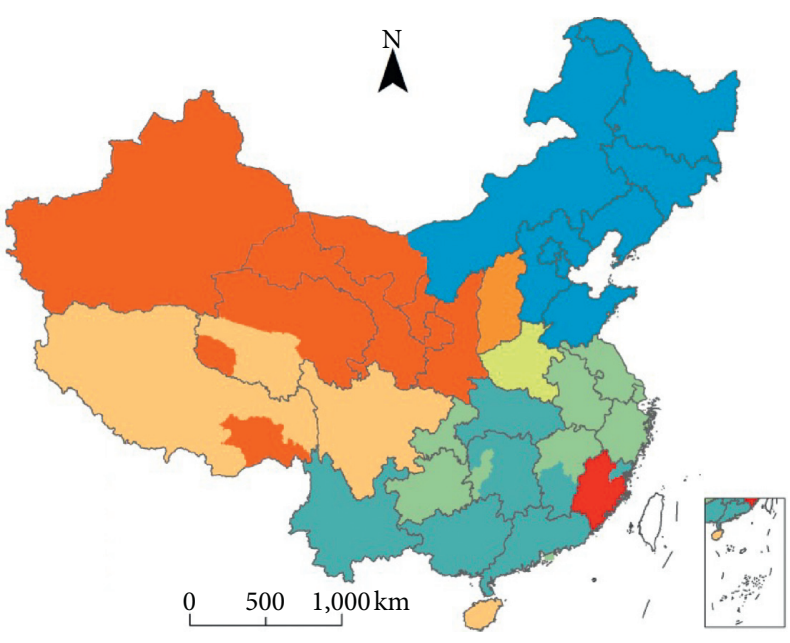

Cluster structure

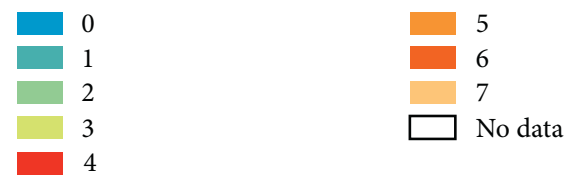

(a) (b)

FIgURE 10: Continued. 

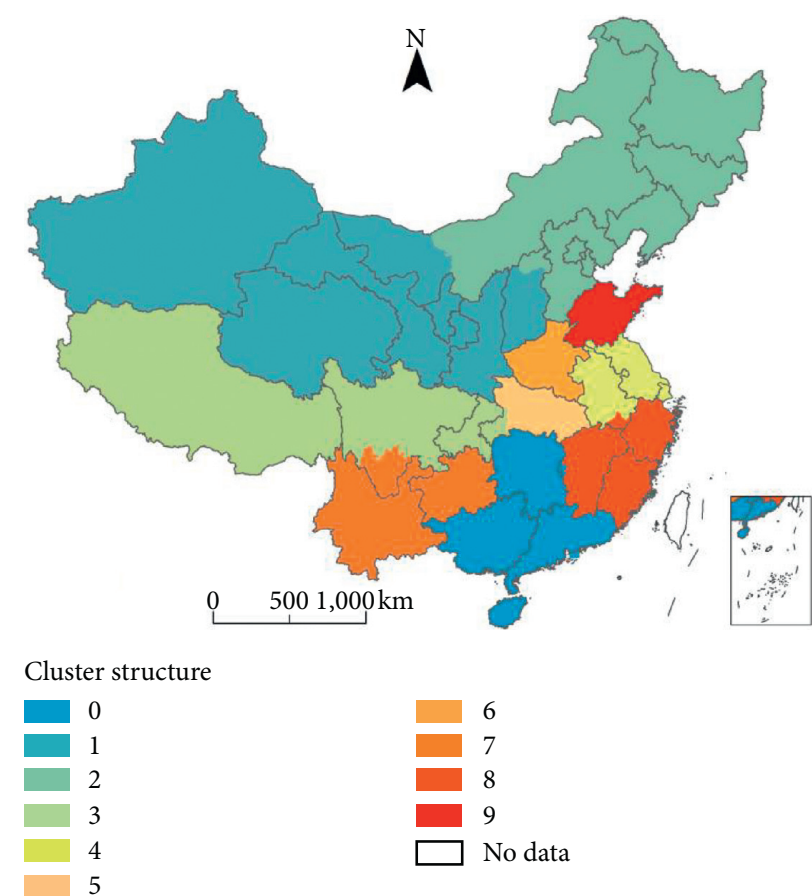

(c)

Figure 10: City network cluster structure in China under different travel modes: (a) aviation; (b) railway; and (c) highway.

highway network and aviation network were identical to the railway network, so they showed a high degree of overlap (red), in which the number of overlapping cities reached 16. Eighty-five cities belong to the same cluster under any two traffic modes, shown in blue, and the remaining cities belong to different clusters under the three traffic modes (Figure 11). Although similarities could be observed in the networks representing three fundamentally different types of interactions, the modular structure was inconsistent, which indicated that there were strong differences in people's choice of travel mode [51].

\section{Discussion}

In the process of calculating the alter-based centrality and alter-based power, we found that when the degree centrality was the same, with the increase of the weighted degree centrality, the status of city also improved [20]. For example, Beijing, Shanghai, Guangzhou, and other cities were all associated with high-intensity population flow, and their alter-based centrality and alter-based power and ranks were pushed up. The network status of Anqing, Qingdao, Nanchang, and other regional central cities improved due to their high correlation and uniform flow distribution. When the dependency parameter was added to equation (3), the centrality with path dependence in a city tended to converge [20]. For example, in the highway trip network, $71.9 \%$ of the population flow in Xianyang was associated with Xi'an, which caused its ranking to decrease by 60 relative to the weighted degree centrality. The alter-based centrality and alter-based power also showed a certain degree of reverse nature. Under the same association weight, cities with more association opportunities were more likely to be connected, but cities with path dependence were easier to control. For example, Lanzhou associates mostly with Tianshui, Xining, Zhongwei, and some cities with low centrality. These cities lack communication opportunities and depended highly on Lanzhou. Thus, the status of Lanzhou's western gateway was promoted. Gateway cities were often the hubs of regional network resource allocation, and have high power over neighboring cities, to some extent. This compressed the opportunity and possibility of residents traveling in the region, showing a monopoly of regional resource circulation. This proved that a large number of small-scale cities (network resources can only be exchanged through gateway cities) had the disadvantages of lacking a path and path dependence.

Chinese people have a strong and unique homeland complex. In this sense, because of the Spring Festival in China, there will be a Spring Festival travel rush in China. The main driving factor of population migration during the Spring Festival travel rush is the imbalance of regional economic development. After China's reform and opening up, the eastern region was given priority of development $[32,52]$. Driven by economic benefits, a large amount of rural surplus labor began to move to the east and other economically developed areas. In the study, we found that the population flow routes were sparse in the west and dense in the east, and the high population flow routes concentrated on the east side of the "Huhuanyong Line," which is consistent with the conclusions of Wei et al. [46]. The economic development of eastern China is relatively fast, with frequent exchanges between cities, and priority given to transportation infrastructure. The economic development of 


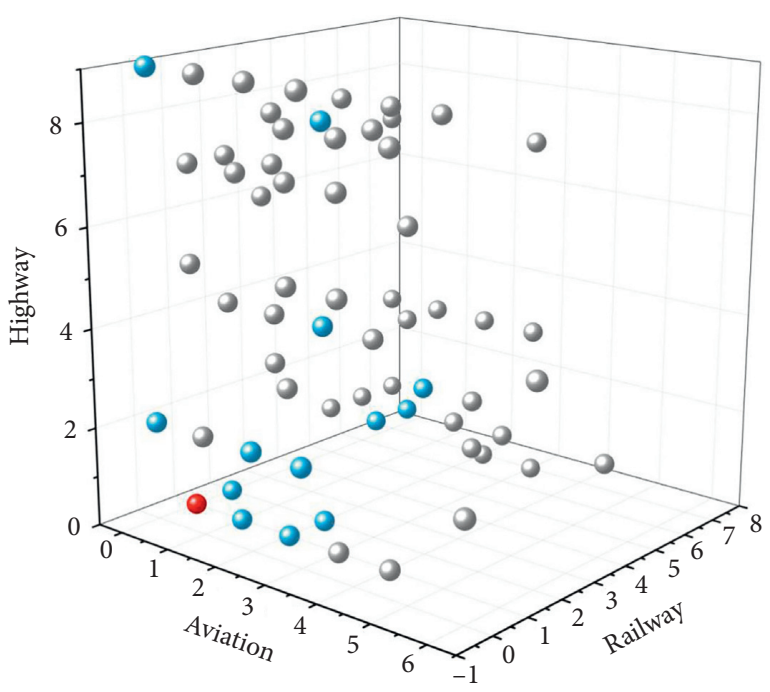

FIgURE 11: Similarity of cluster structure in the travel modes of aviation, railway, and highway. The cell colors indicate the type of overlap between the three cluster structures. Gray, blue, and red, respectively, indicate that the three cluster structures completely overlap, that two overlap, and that none overlap.

northwestern China is backward and construction is difficult. In view of this, the government should support and improve northwestern transportation routes, improve the convenience of travel, and reasonably plan and arrange the routes. At the same time, it is also necessary to adapt to local conditions and promote economic construction in the west to reduce population outflow. In the analysis of alter-based centrality and alter-based power, we know that although Chengdu and Chongqing are in the western region, they are ranked highly. Chongqing, in particular, is a province with a large population output, which is consistent with the research results of Lai and Pan [3], This phenomenon makes the development of the urban network in this region appear "faulty." The development of surrounding cities is limited, and resources and development opportunities are concentrated in Chengdu and Chongqing because of the lack of a pivot point. In order to alleviate this phenomenon, it is necessary to spread the functions of the cities (Chengdu and Chongqing) to the surrounding region [46]. Population migration brings not only economic development and regional exchanges but also disease transmission, employment, and traffic pressure. Therefore, the government should regularly detect population flows, predict their trends in the next period, and make plans for the occurrence and prevention of emergencies in advance [1]. In addition, population flow can reflect the development of urban agglomerations. That is, the closer the connections between cities, the better the development of urban agglomerations. In future work, we can reduce the attention on individual cities, and instead consider using population flow data to measure the development of urban agglomerations and the internal and external relations of urban agglomerations.

This study compared and analyzed the structural characteristics of intercity networks under multiple travel modes. We improved the unilateral and attribute-oriented defects caused by existing research relying on a single type of travel mode. Tencent Migration data broke through the lag effect brought by traditional statistical data and provided a new data source for large-scale research on intercity travel by the Chinese. Compared with other data, Tencent had more users and higher accuracy. However, due to the generation and acquisition of the data and the protection of personal privacy, it was impossible to obtain social attributes such as the occupation, sex, age, and travel purposes of travelers. It was impossible to further explore the willingness and group effect of the population. In addition, some travel paths may be disassembled, and the origin and destination cannot be studied as network nodes. The status of a transit city was overemphasized, the trip characteristics of users cannot be identified completely, and the spatial characteristics of multiple trips by residents cannot be identified. This will inevitably cause errors in the research results. As a representative period of holidays, the Spring Festival is special. However, we cannot ignore the impact of population flow in other periods on Chinese economic development. Pan and Lai [1] used the same data to study the time series characteristics and scale of population flow on National Day and the subsequent Mid-Autumn Festival. It was concluded that the performance of population flow in this period is quite different from that in the Spring Festival travel rush. In future work, it will be necessary to comprehensively analyze the characteristics of Chinese population flow in combination with multiple time periods, and to clarify the differences between other time periods and the Spring Festival travel rush. In addition, on the basis of continuous time series data, we will excavate the evolution process and formation mechanism of the intercity trip network of Chinese residents. In this study, we discussed the structure of the population trip network based on the macro-characteristics of the floating population under different travel modes, and the spatial pattern of the urban network structure. However, there was no fusion comparison of the multisource data. With the rapid development of geographic big data, it is necessary to use intelligent technology to compare the differences in population flow under multisource data, and to explore more useful knowledge. This study provided a new perspective for the perception of human social activities, that is, big data, and points out a new research idea for global scientific researchers to study human social activity.

\section{Conclusions}

In this study, we used data from population migration trajectories between cities provided by the Tencent Migration big data platform. Spatial analysis was used to explore the characteristics of an intercity trip network of the Chinese under different travel modes during the Spring Festival travel rush. We determined the hierarchy of this urban network and measured the agglomerated spatial patterns under different travel modes with the help of two indicators: the alter-based centrality and alter-based power. The main conclusions were as follows: 
(1) Among the three travel modes, the fewest routes were connected by aviation (8451), followed by highways $(10,222)$ and railway $(13,746)$. When a trip involved traveling less than $350 \mathrm{~km}$, travelers tended to use highways. When trips covered distances less than $1,500 \mathrm{~km}$, railways were the most popular mode of travel, and when the distance was 1,000-1,500 km, aviation was the most popular. In terms of the number of passengers, railways transport the most people, followed by highways and aviation. Among the maximum dominant flow, Beijing and Shanghai played the most important role in controlling domestic aviation trip connections, followed by Chengdu and Chongqing. For railway trips, Beijing and Chengdu occupied the absolute advantage, whereas highways were mostly used for connections between provincial administrative centers and the surrounding cities.

(2) According to the indicators of alter-based centrality and alter-based power, cities could be divided into four types: quintessential cities, hub cities, gateway cities, and edge cities. In the aviation city network, the ratio of the number of cities among these four types was $23: 7: 7: 309$, with the largest number of other-level edge cities. In the railway network, the ratio of the number of cities among these four types was $33: 37: 15: 261$. The number of other-level edge cities decreased significantly, and the number of quintessential cities increased significantly. The number of quintessential cities at the local level was the largest under the highway mode of travel. The number of hub cities was 80 , with a similar number of gateway cities.

(3) During the Spring Festival travel rush, the number of urban clusters under different travel modes was different. Aviation, railway, and highway trips are clustered into 7, 8, and 10 urban clusters in sequence. In the space display, there were fewer categories, discontinuous clusters, fewer geographical constraints, and jump distributions in the aviation travel mode. The cluster structure in the railway travel mode had an aggregation state and high spatial connectivity. The cluster structure under the highway travel mode appeared as a block distribution, and the coincidence degree between the cluster boundary and the provincial boundary was higher.

(4) There were differences in the characteristics of the urban network from the perspective of the different modes of travel. Intercity population flow based on aviation trips was highly polarized with discrete point embedding, reflecting a core-periphery structure with nationwide-level hub cities as the core distribution. The intercity population flow based on railway trips had a core-periphery structure that took cities along the national railway artery as the core and gradually decreased to the hinterland cities. The intercity population flow based on highway trips had a spatial pattern of strong local aggregation that matched with the population scale.

\section{Data Availability}

Tencent's population migration data are obtained from the location big data released by Tencent Company, which comes from https://heat.qq.com/qianxi.php.

\section{Conflicts of Interest}

The authors declare that there are no conflicts of interest regarding the publication of this paper.

\section{Acknowledgments}

This work was supported by the National Natural Science Foundation of China (Grant no. 41661025).

\section{References}

[1] J. Pan and J. Lai, "Spatial pattern of population mobility among cities in China: case study of the national day plus mid-autumn festival based on Tencent migration data," Cities, vol. 94, pp. 55-69, 2019.

[2] J. Xu, A. Li, D. Li et al., "Difference of urban development in China from the perspective of passenger transport around Spring Festival," Applied Geography, vol. 87, pp. 85-96, 2017.

[3] J. B. Lai and J. H. Pan, "China's city network structural characteristics based on population flow during spring festival travel rush: empirical analysis of "tencent migration" big data," Journal of Urban Planning and Development, vol. 146, no. 4, Article ID 04020018, 2020.

[4] W. Zhang, Z. Chong, X. Li, and G. Nie, "Spatial patterns and determinant factors of population flow networks in China: analysis on Tencent location big data," Cities, vol. 99, Article ID 102640, 2020.

[5] D. N. Garrett, R. Alasdair, and J. L. Rosenbloom, "An economic geography of the United States: from commutes to megaregions," PLoS One, vol. 11, no. 11, Article ID e0166083, 2016.

[6] Y. Wei, W. Song, C. Xiu, and Z. Zhao, "The rich-club phenomenon of China's population flow network during the country's spring festival," Applied Geography, vol. 96, pp. 77-85, 2018.

[7] Y. Long, "Redefining Chinese city system with emerging new data," Applied Geography, vol. 75, pp. 36-48, 2016.

[8] J. Shen, "Explaining interregional migration changes in China, 1985-2000, using a decomposition approach," Regional Studies, vol. 49, no. 7, pp. 1176-1192, 2013.

[9] J. Qi, Z. Wang, Y. Wang, and D. Li, "Visualization and analysis on the spatial-temporal patterns of flow direction of interprovincial migration in China based on origin-destination matrix," Procedia Environmental Sciences, vol. 26, pp. 115-118, 2015.

[10] S. Dong, Y. Pu, and Y. Wang, "A research on complex network of Chinese interprovincial migration based on the fifth population census," in Proceedings of the 2013 21st International Conference on Geoinformatics, pp. 1-4, Kaifeng, China, June 2013. 
[11] Y. Wang, L. Dong, Y. Liu, Z. Huang, and Y. Liu, "Migration patterns in China extracted from mobile positioning data," Habitat International, vol. 86, pp. 71-80, 2019.

[12] Y. Wang, F. Wang, Y. Zhang, and Y. Liu, "Delineating urbanization "source-sink" regions in China: evidence from mobile app data," Cities, vol. 86, pp. 167-177, 2019.

[13] T. Lv, X. F. Piao, W. Y. Xie, and S. B. Huang, "Study of the attack-resistance of national economy based on data mining analysis of the population flow social network," in Proceedings of the 2011 International Conference on E-Business and E-Government (ICEE), Shanghai, China, May 2011.

[14] X. Liu, Z. Neal, and B. Derudder, "Featured graphic. City networks in the United States: a comparison of four models," Environment and Planning A: Economy and Space, vol. 44, no. 2, pp. 255-256, 2012.

[15] X. Li, S. Huang, J. Chen, and Q. Chen, "Analysis of the driving factors of US domestic population mobility," Physica A: Statistical Mechanics and its Applications, vol. 539, Article ID 122984, 2020.

[16] Z. Xu and R. Harriss, "Exploring the structure of the U.S. intercity passenger air transportation network: a weighted complex network approach," GeoJournal, vol. 73, no. 2, pp. 87-102, 2008.

[17] F. Zhen, Y. Cao, X. Qin, and B. Wang, "Delineation of an urban agglomeration boundary based on Sina Weibo microblog "check-in" data: a case study of the Yangtze River Delta," Cities, vol. 60, pp. 180-191, 2017.

[18] H. Roberts, J. Sadler, and L. Chapman, "Using Twitter to investigate seasonal variation in physical activity in urban green space," Geo: Geography and Environment, vol. 4, no. 2, Article ID e00041, 2017.

[19] J. Li, H. V. Zuylen, C. H. Li, and S. F. Lu, "Monitoring travel times in an urban network using video, GPS and Bluetooth," Procedia Social and Behavioral Sciences, vol. 20, pp. 630-637, 2011.

[20] Z. Y. Zhao, Y. Wei, S. J. Wang, and R. Q. Pang, "Measurement of directed alternative centricity and power of directed weighted urban network: a case of population flow network of China during "Chunyun" Period," Geographical Research, vol. 36, no. 4, pp. 647-660, 2017, in Chinese.

[21] H. L. Boschken, "A multiple-perspectives construct of the American global city," Urban Studies, vol. 45, no. 1, pp. 3-28, 2008.

[22] A. S. Alderson and J. Beckfield, "Power and position in the world city system," American Journal of Sociology, vol. 109, no. 4, pp. 811-851, 2004.

[23] B. Derudder, M. Timberlake, and F. Witlox, "Introduction: mapping changes in urban systems," Urban Studies, vol. 47, no. 9, pp. 1835-1841, 2010.

[24] K. S. Cook, R. M. Emerson, M. R. Gillmore, and T. Yamagishi, "The distribution of power in exchange networks: theory and experimental results," American Journal of Sociology, vol. 89, no. 2, pp. 275-305, 1983.

[25] Z. Neal, "Differentiating centrality and power in the world city network," Urban Studies, vol. 48, no. 13, pp. 2733-2748, 2011.

[26] Z. Neal, "Does world city network research need eigenvectors?” Urban Studies, vol. 50, no. 8, pp. 1648-1659, 2013.

[27] H. Yang, F. Dobruszkes, J. Wang, M. Dijst, and P. Witte, "Comparing China's urban systems in high-speed railway and airline networks," Journal of Transport Geography, vol. 68, pp. 233-244, 2018.

[28] B. J. L. Berry, "Cities as systems within systems of cities," Papers of the Regional Science Association, vol. 13, no. 1, pp. 146-163, 1964.
[29] P.-A. Laharotte, R. Billot, E. Come, L. Oukhellou, A. Nantes, and N.-E. El Faouzi, "Spatiotemporal analysis of bluetooth data: application to a large urban network," IEEE Transactions on Intelligent Transportation Systems, vol. 16, no. 3, pp. 1439-1448, 2015.

[30] B. Derudder and Z. Neal, "Uncovering links between urban studies and network science," Networks and Spatial Economics, vol. 18, no. 3, pp. 441-446, 2019.

[31] Z. P. Neal, "From central places to network bases: a transition in the US Urban hierarchy, 1900-2000," City \& Community, vol. 10, no. 1, pp. 49-75, 2010.

[32] J. Li, Q. Ye, X. Deng, Y. Liu, and Y. Liu, "Spatial-temporal analysis on spring festival travel rush in China based on multisource big data," Sustainability, vol. 8, no. 11, p. 1184, 2016.

[33] M. Castells, "Globalisation, networking, urbanisation: reflections on the spatial dynamics of the information age," Urban Studies, vol. 47, no. 13, pp. 2737-2745, 2010.

[34] W. Cheng, C. L. Xiu, W. Q. Ke, Z. Y. Yu, and Y. Wei, "Hierarchical structures of China's city network from the perspective of multiple traffic flows," Geographical Research, vol. 34, no. 11, pp. 2073-2083, 2015, in Chinese.

[35] Y. Lu and Y. Liu, "Pervasive location acquisition technologies: opportunities and challenges for geospatial studies," Computers, Environment and Urban Systems, vol. 36, no. 2, pp. 105-108, 2012.

[36] H. Yang, G. Burghouwt, J. Wang, T. Boonekamp, and M. Dijst, "The implications of high-speed railways on air passenger flows in China," Applied Geography, vol. 97, pp. 1-9, 2018.

[37] S.-L. Shaw and H. Yu, "A GIS-based time-geographic approach of studying individual activities and interactions in a hybrid physical-virtual space," Journal of Transport Geography, vol. 17, no. 2, pp. 141-149, 2009.

[38] Y. Z. Liu, W. T. Zhang, X. M. Cui, G. D. Zhang, and G. X. Wang, "City pipe network intelligent service based on GIS and Internet of Things," in Proceedings of the 2014 7th International Conference on Intelligent Computation Technology and Automation, Changsha, China, October 2014.

[39] J. Wang and F. Jin, "China's air passenger transport: an analysis of recent trends," Eurasian Geography and Economics, vol. 48, no. 4, pp. 469-480, 2007.

[40] J. Li, X. Wen, M. Wu, F. Liu, and S. Li, "Identification of key nodes and vital edges in aviation network based on minimum connected dominating set," Physica A: Statistical Mechanics and Its Applications, vol. 541, Article ID 123340, 2020.

[41] W. Cao, X. Feng, and H. Zhang, "The structural and spatial properties of the high-speed railway network in China: a complex network perspective," Journal of Rail Transport Planning \& Management, vol. 9, pp. 46-56, 2019.

[42] J. Wang, D. Du, and J. Huang, "Inter-city connections in China: high-speed train vs. inter-city coach," Journal of Transport Geography, vol. 82, Article ID 102619, 2020.

[43] N. Limtanakool, M. Dijst, and T. Schwanen, "A theoretical framework and methodology for characterising national urban systems on the basis of flows of people: empirical evidence for France and Germany," Urban Studies, vol. 44, no. 11, pp. 2123-2145, 2007.

[44] A. De Montis, S. Caschili, and A. Chessa, "Time evolution of complex networks: commuting systems in insular Italy," Journal of Geographical Systems, vol. 13, no. 1, pp. 49-65, 2010.

[45] Z. Neal, "The devil is in the details: differences in air traffic networks by scale, species, and season," Social Networks, vol. 38, pp. 63-73, 2014. 
[46] Y. Wei, C. L. Xiu, Z. M. Liu, and W. Chen, "“'Spatial pattern of city network in transitional China based on the population flows in "Chunyun" period," Scientia Geographica Sinica, vol. 36, no. 11, pp. 1654-1660, 2016, in Chinese.

[47] J. D. Nystuen and M. F. Dacey, "A graph theory interpretation of nodal regions," Papers in Regional Science, vol. 7, no. 1, pp. 29-42, 2005.

[48] J. O. Wheeler and R. L. Mitchelson, "Information flows among major metropolitan areas in the United States," Annals of the Association of American Geographers, vol. 79, no. 4, pp. 523-543, 1989.

[49] V. D. Blondel, J.-L. Guillaume, R. Lambiotte, and E. Lefebvre, "Fast unfolding of communities in large networks," Journal of Statistical Mechanics: Theory and Experiment, vol. 2008, no. 10, Article ID P10008, 2008.

[50] S. A. Tabrizi, A. Shakery, M. Asadpour, M. Abbasi, and M. A. Tavallaie, "Personalized PageRank clustering: a graph clustering algorithm based on random walks," Physica A: Statistical Mechanics and its Applications, vol. 392, no. 22, pp. 5772-5785, 2013.

[51] L. Hedayatifar, R. A. Rigg, Y. Bar-Yam, and A. J. Morales, "US social fragmentation at multiple scales," Journal of The Royal Society Interface, vol. 16, no. 159, Article ID 20190509, 2019.

[52] J. Shen, "Increasing internal migration in China from 1985 to 2005: institutional versus economic drivers," Habitat International, vol. 39, pp. 1-7, 2013. 